\title{
A Quantitative Investigation of the Laffer Curve on the Continued Work Tax : The French Case
}

\author{
Jean-Olivier Hairault ${ }^{1}$ \\ François Langot ${ }^{2}$ \\ Thepthida Sopraseuth ${ }^{3} 4$
}

$\mathrm{N}^{\circ}: 2004-09$

\footnotetext{
${ }^{1}$ University of Paris I, EUREQUA and CEPREMAP. Email : joh@univ-paris1.fr

${ }^{2}$ University of Maine, GAINS and CEPREMAP. Email : flangot@univ-lemans.fr

${ }^{3}$ University of Evry, EPEE and CEPREMAP. Email : tsoprase@univ-evry.fr

${ }^{4}$ Corresponding author : EPEE, Département d'Economie, Université d'Evry Val d'Essonne, 4 Bd F. Mitterand, 91025 Evry Cedex. Tel : 331694770 46. Fax : 331694770 50. Email : thepthida.sopraseuth@univevry.fr. The authors acknowledge financial support from the Commissariat Général au Plan, Contrat finalisé 2002. We benefited from fruitful discussions with L. Caussat, P. Y. Hénin, T. Japelli, M. Pagano, P. Pestieau, B. Sédillot, E. Walraet and T. Weitzenblum. We thank seminar participants at the EEA Congress (Stockholm, 2003), ESEM (Madrid, 2004) the Society for Computational Economics meeting (Seattle, 2003), the CSEF (Naples, 2003), the SED meeting (Paris, 2003), the workshop on intergenerational transfers (Paris, 2003), the Association Française des Sciences Economiques (Paris, 2003), the Scientific Workshop of the Caisse des Dépôts et Consignations (Bordeaux, 2003), T2M (Orléans, 2004) and Fourgeaud seminar (Paris, 2003). Errors and omissions are ours.
} 
JO Hairault, F. Langot , T. Sopraseuth

\title{
Une évaluation quantitative de la Courbe de Laffer sur la taxe à l'activité prolongée : Le cas Français
}

Résumé : Certains avancent que la taxe sur l'activité prolongée devrait être supprimée grâce à l'introduction de barèmes de pension de retraite actuariellement neutres. Cependant, par défition, ce type de barème ne permet pas de financer le déficit futur des systèmes de pension de retraite par répartition. Cet article propose de donner aux individus seulement une partie du barème actuariellement neutre afin de les inciter à partir à la retraite plus tard. La caisse d'assurance vieillesse arbitre donc entre accorder davantage d'incitations financières pour inciter les individus à retarder leur départ en retraite et réduire ces incitations pour financer son déficit. Cet arbitrage conduit à une courbe de Laffer que nous évaluons sur données françaises. Nous étudions par ailleurs les interactions entre la richesse et les décisions de départ en retraite.

Mots clés : retraite, richesse, neutralité actuarielle.

\section{A Quantitative Investigation of the Laffer Curve on the Continued Work Tax : The French Case}

\begin{abstract}
It is often argued that the tax on continued work should be removed by implementing actuarially fair schemes. However, these schemes cannot help finance the expected Social Security deficit. This paper proposes to give individuals only a fraction of the marginal actuarially fair incentives in case of postponed retirement. Social Security then faces a trade off between giving enough incentives to make individuals actually delay retirement and giving little increase in pensions in order to help finance its expected deficit. This trade-off is captured by a Laffer curve that we quantify on French data. Furthermore, we analyze the interactions between wealth and retirement behavior.
\end{abstract}

Keywords : retirement behavior and wealth, actuarially fair benefits.

JEL Classification : H31, H55, J26 


\section{Introduction}

As underlined by Gruber and Wise [1998], Social Security provisions, especially defined pension plans, impose strong constraints on retirement decisions. The pattern of Social Security benefits reveals the presence of an implicit tax on continued work beyond the normal retirement age: continuation in the labor force implies a reduction in the change in present discounted values of pension benefits, due to insufficient actuarial adjustment for fewer years of pension receipt. Gruber and Wise [1998] stress that this implicit tax on continued work, combined with generous replacement rates for retirees and high social security payroll (explicit) taxes for workers, gives strong incentives to leave early the labor force.

With the implicit tax on continued work and the strong decrease in benefits in case of early retirement, the current system does not accommodate the diversity in life expectancy and preferences. It is thus often argued that Social Security provisions should be actuarially neutral at the margin: additional contributions by working another year and the foregone pension due to this delayed retirement should be exactly matched by an increase in the value of the pension received over the shorter retirement period. Pension wealth then increases with continued work and compensate the worker for the lower life expectancy when she postpones retirement. Drastic Social Security reforms such as in Sweden and Italy could be viewed as an attempt to implement a pension system with an actuarially fair flavor.

However, by definition, this actuarially fair scheme does not help finance the expected Social Security deficit inherent in aging economies. Indeed, the actuarially fair provision equalizes discounted expected expenditures (increased pensions when retirement is postponed) to the additional Social Security revenue (foregone pension and contribution during the continuing working year). In the public finance view adopted in this paper, the actuarially fair scheme constitutes an upper bound on the additional pension paid to individuals who work longer. This paper proposes to give individuals only a fraction of the actuarially fair incentives in case of postponed retirement. As a result, if individuals are responsive to the incentive schemes by delaying retirement, they still earn an additional pension (even though this benefit is below the actuarially fair level). Besides, the Social Security gets additional revenue to help finance its expected deficit.

Under a public finance perspective, what is the suitable fraction of the actuarially fair scheme individuals should be given? It is then fairly intuitive that the Social Security faces a trade off between giving enough incentives to make individuals actually delay retirement and giving little increase in Social Security provisions in order to help finance the expected deficit of the PAYG system. This trade-off is captured by a Laffer curve. This paper proposes to quantify the magnitude of this Laffer curve effect. Our quantitative exercise relies on French data. Indeed, France is an extreme case of defined pension plans such that little freedom is left to individuals as far as retirement decisions is concerned. This paper is an attempt to assess what would happen if France were to adopt incentive schemes (i.e. a reduced implicit tax on continued work) and to what extent they can contribute to help finance expected deficits.

Beyond the public finance implications, incentives scheme could induce much more heterogeneity in retirement ages. In particular, it certainly leads to boost the role of wealth. Our model illustrates the role of wealth and incentive benefits in generating heterogeneous retirement behavior. Indeed, as a source of heterogeneity, the model takes into account only the various employment status at the end of working life, thereby discarding the heterogeneity due to other factors such as health, incomplete careers or female specific labor participation. In spite 
of this streamlined heterogeneity, the interaction between incentive schemes and wealth yields very heterogeneous retirement ages.

The modeling strategy relies on two strands of the literature.

- The first one (initiated by Stock and Wise [1990] and Rust [1989], Berkovic and Stern [1991], Rust and Phelan [1997]) improves our understanding of retirement choices in life cycle models with uncertain life time and future income. Nevertheless, studies of retirement assume that capital markets are perfect, so that saving and consumption decisions are made in the background and do not affect retirement decisions.

- The second strand of the literature examines the macroeconomic impact of funded versus unfunded retirement systems (see Imrohoroglu, Imrohoroglu and Joines [1999] for a survey). This literature develops overlapping generation models with borrowing constraints, altruism along with several sources of uncertainty. These heterogenous agent models allow to replicate salient features of the wealth distribution and measure the consequences of various retirement systems on the capital stock. In addition, wealth accumulation constitutes an alternative to mandatory pay-as-you go systems to smooth lifetime consumption. Wealth accumulation thereby constitutes an essential element when analyzing retirement decisions. However, these studies take retirement behavior to be fixed.

Studies of retirement and saving seem to be conducted independently of each other. This paper tries to merge both literatures by taking into account the interaction between wealth and retirement decisions. Recent papers tackle this issue (see Diamond and Hausman [1984] and Kahn [1988] for previous work, Coile, Diamond, Gruber and Jousten [2002], VanDerKlaauw and Wolpin [2002] and Gustman and Steinmeier [2002]). The originality of our work lies in the analysis of how altruism and social mobility across generations affects wealth decisions and retirement behavior. Along these lines, we extend Fuster [1999] and Fuster, Imrohoroglu and Imrohoroglu [2003] analysis of the role of altruism on social security reform to retirement decisions.

We show in a stationary regime that the implicit tax on continued work inherent to the current social security scheme leads the French economy to be located on the right side of the Laffer curve: from a public finance point of view, it is efficient to reduce this tax by allowing agents who decide to delay their retirement to receive additional pensions. A large fraction of the actuarially fair scheme must be given to these agents in order to maximize the expected total deficit reduction when the PAYG system is maintained. This is why the incentive scheme policy can only finance around $10 \%$ of the expected deficits. We also show that capitalizing the surplus provided by later retirements on the financial market ("mandatory funded system at the margin") improves the efficiency to this policy: a lower fraction of the actuarial fair scheme given to individuals scheme now corresponds to the maximum of the Laffer curve.

We find that retirement decision and wealth accumulation are strongly related once incentive schemes are introduced. This suggests that taking into account wealth accumulation is crucial in assessing Social Security reforms. Starting from the current homogenous retirement behaviors, we show that introducing incentives leads to much more diversity, in particular due to wealth heterogeneity across agents. Wealth favors early retirement as individuals are rich enough to bear the reduced pension associated with early retirement. Because there is some heterogeneity in social mobility across agents, altruism leads to wealth heterogeneity, thus to disparity in 
retirement behavior. By encouraging wealth accumulation, high altruism penalizes the incentive policy in a stationary regime.

The paper is organized as follows. We present our benchmark model (section 2), its calibration (section 3) and its consistency with actual data (section 3.2). We then gauge the impact of incentive schemes on retirement behavior and Social Security budget (section 4). Section 5 proposes a quantitative evaluation of the Laffer curve on the continued work tax. Section 6 concludes.

\section{The benchmark model}

The model analyzed in this section is a modified version of the stochastic neoclassical growth model with uninsured idiosyncratic risk and no aggregate uncertainty. Beyond the heterogeneity arising from uninsurable shock to household employment opportunities, life cycles features are also considered. Following here Castañeda, Diaz-Gimenez and Rios-Rull [1998], agents age stochastically. Upon death, households are replaced by other households of the same dynasty and are imperfectly altruistic towards them. Finally, like in Rust and Phelan [1997], retirement decisions are endogenous. From the age of 59 on, each year, the individual decides to retire the following year or remain in her current situation : employed, pre-retired or unemployed. This theoretical framework extends Rust and Phelan [1997]'s model to allow for wealth accumulation.

A last important feature of the model is the social structure adopted in this paper. For the calibration of the model, we rely on French statistics that categorize the population according to their skill level. Since we are interested in the reforms affecting workers of the private system (that covers $70 \%$ of the labor force), we retrain 3 broad categories: blue collar (unskilled workers and clerks) workers ${ }^{5}$, white collar workers including (intermediate skilled) employees (or middle white collars) and (high skilled) executives. Wage profiles and levels, replacement rates, unemployment and pre-retirement transitions, mortality risk and age of end of education are specific to each social category. Finally, the model will be able to predict the retirement decision of each occupational group.

\subsection{The life cycle model and employment opportunities}

In this section, we define the exogenous stochastic variables of the model, namely the age of households, their employment opportunities and intergenerational social mobility. These stochastic processes are independent of each other.

\subsubsection{Life Cycle}

Each period, some households are born and some households die. For empirical reasons, we assume that there is no demographic growth. Households are born as workers. For sake of simplicity, individuals face a mortality from age $59 \mathrm{on}$. In order to take into account a typical wage life-cycle profile, we assume that the population can be divided into three classes of age, the young, the adult and the mature individuals respectively denoted $J, A$ and $M$. As a worker accumulates experience during his life-cycle, we assume that the efficiency of the labor input

\footnotetext{
${ }^{5}$ Blue collars and clerks are merged into the same category as their characteristics in terms of unemployment risk and life expectancy are found to be rather similar in French statistics.
} 
grows with the age of the agents. Thus, when a young worker becomes an more experienced worker, his efficiency is multiplied by $1+x_{J}$. When an young worker becomes an adult worker, his efficiency is multiplied by $1+x_{A}$, with $x_{J}<x_{A}$. The same process applies to mature people. The mature period encompasses the ages of 59 to $70,(M=\{59,60, \ldots, 70\})$. Since the legal retirement age is fixed to 60 , from the age of 59 on, each agent chooses to remain in her current state (employed, pre-retired or unemployed) or retire the following period.

Each individual is born as a young worker. The probability of remaining a young (experienced) worker the next period is $\pi_{J J}\left(\pi_{A A}\right)$. Conversely, the probability of becoming an experienced (old) worker is $1-\pi_{A A}\left(1-\pi_{J J}\right)$. From the age of 59 on, the individual of age $z \geq 59$ faces a rising probability to die $\left(1-\pi_{M z}\right)$. The mortality matrix takes into account the inequality between blue collars and white collars: under the benchmark calibration, unskilled workers' expected duration of retirement equals 18 years while executives enjoy 24 years of retirement on average. The matrix governing the age Markov-process is given by:

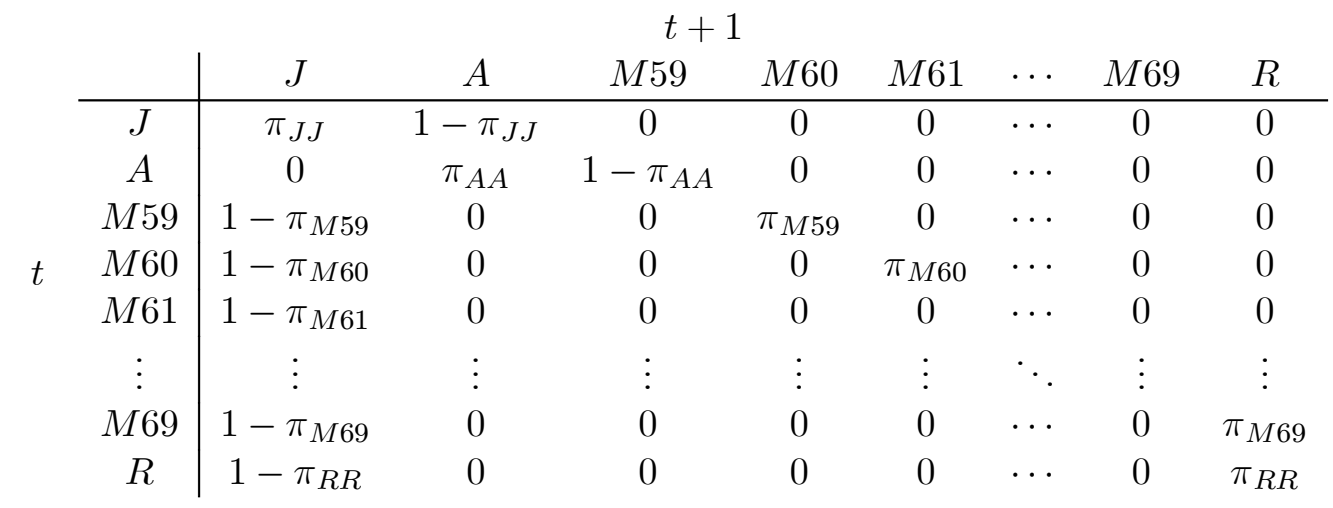

\subsubsection{Employment opportunities}

There are three components in the real wage : a deterministic exogenous productivity trend growing at a rate of $\gamma$, the experience component which profile has been described above, and an idiosyncratic risk. In order to simplify our analysis, this idiosyncratic element of the real wage intervenes at the age of 59 only. When young or adult, people do not face the risk of being unemployed. At the age of 59 , some agents become unemployed $(U)$ and pre-retired $(P)$. We discard unemployment risks during the early stages of working life because, in France, periods of unemployment are included in the number of contributive years to the Social Security system. As a result, the pension is moderately affected by unemployment periods. However, we consider unemployment and pre-retirement risks at the end of the working life. Indeed, labor status is a key element in retirement decisions as it determines current and future income flows. In addition, in Europe, and more particularly in France, only half of retirees were employed before deciding to retire, the other half being pre-retired or unemployed. Taking into account the idiosyncratic risk of being employed, unemployed or pre-retired is then essential in the understanding of retirement decisions, especially when a more actuarially fair pension system is present.

Transitions to states $U$ and $P$ are determined by exogenous probabilities denoted by $\pi_{u}$ and $\pi_{p}$. Once pre-retired or unemployed, the individual remains pre-retired or unemployed, which is consistent with the French statistics. Exogenous transitions to pre-retirement or unemployment are specific to each social group : in particular, blue-collars and clerks face a higher risk of inactivity than white collars. 
Finally, we assume that a newly-born household's social status is determined by her parents' rank. This social mobility is modelled by an exogenous Markov matrix

$$
\pi\left(\epsilon^{\prime} \mid \epsilon\right)=\operatorname{Pr}\left\{\epsilon_{i t+1}=\epsilon_{i}^{\prime} \mid \epsilon_{i t}=\epsilon_{i}\right\}
$$

where $\epsilon_{i}\left(\epsilon_{i}^{\prime}\right)$ denotes the random variable embodying the social status of the father (of the son). It is assumed that, once born with a random social status (linked to that of her father), an individual's social status is not modified in her life-time.

\subsection{The household's decision: retirement choice, consumption and wealth}

\subsubsection{Preferences}

Households only derive utility from their consumption when their are alive as well as from the consumption of their progenies. The intertemporal utility function of an household is given by

$$
\sum_{t=0}^{\infty} \beta^{t}\left\{\sum_{s_{t} \in \mathcal{V}} \pi\left(s_{t} \mid s_{t-1}\right) u\left(C_{t}, l_{t}\right)+\left(1-\sum_{s_{t} \in \mathcal{V}} \pi\left(s_{t} \mid s_{t-1}\right)\right) \eta \sum_{s_{t} \in S 1} \pi\left(s_{t+1} \mid s_{t}\right) \beta V\left(A_{t+1}, s_{t+1}\right)\right\}
$$

where the period utility function $u$ is strictly concave, the time-discount factor verifies $\beta \in] 0,1[$, consumption $C_{t}$ and leisure $l_{t}$ are positive. The variable $s_{t} \in S$ is a compact notation to denote the age, the employment opportunities and the social mobility of the household. This variable follows a finite state Markov chain with conditional transition probability given by

$$
\pi\left(s^{\prime} \mid s\right)=\operatorname{Pr}\left\{s_{t+1}=s^{\prime} \mid s_{t}=s\right\}
$$

We denote $\mathcal{V} \in S$ the set of all the possible states $s$ of being alive. Finally, the last term of the intertemporal utility function describes the utility derived by the parents from their bequests. The parameter $\eta>0$ is related to the household concern for the welfare of his off-spring and then catches the degree of altruism in the economy. Thus, $V\left(A_{t+1}, s_{t+1}\right)$ denotes the expected utility of a new-born child who begins his career according to a stochastic productivity ladder linked to that of her parents, conditionally on his age, and inherits a stock of wealth $A_{t+1}$. We assume that the instantaneous utility function $u$ is a CRRA:

$$
u(c)=\frac{\left(c^{1-\nu}(1-l)^{\nu}\right)^{1-\tilde{\sigma}}}{1-\tilde{\sigma}}
$$

with $\tilde{\sigma}$ the risk aversion, $l$ indivisible labor and $\nu$ the share of leisure in the instantaneous utility. In addition, the household faces two sources of capital market inefficiency. The first stems from market incompleteness that prevents them from insuring against idiosyncratic risks. The second relies on a liquidity constraint : household are not allowed to run into debt $\left(A_{t+1} \geq 0\right)$.

\subsubsection{The stationary dynamic program}

In order to define a stationary equilibrium, we divide all the variables by the gross rate of technological progress $(1+g)$. We denote stationary consumption and wealth by

$$
c=C_{t} /(1+g)^{t} \text { and } a=A_{t} /(1+g)^{t}
$$


whereas the real wage and the pension are denoted in stationary terms by

$$
w=w_{t} /(1+g)^{t}, \quad \omega(s)=\omega_{t}(s) /(1+g)^{t},
$$

The household of age $z$ has 2 state variables : the pair $(a, s)$ which includes the realization of the household-specific process $s$ and the beginning-of-period capital stock. The dynamic program solved by a household differs according to her age and employment status (retiree / non retiree). Retirement decisions are endogenous. Population dynamics and the distribution of employed, unemployed and pre-retired people are therefore affected by retirement behavior. All agents determine their optimal saving and consumption profile taking into account financial market incompleteness and the borrowing constraint.

From the age of 59 on, individuals of age $z \geq 59$ choose whether to retire or not the following year by comparing the expected future value function at age $z+1$ when retired to the future value function at age $z+1$ if she remains in current state (employed, pre-retired or unemployed). When retired, individuals only choose their optimal consumption and the bequest. Since the households' decision problem is a finite-state, discounted dynamic program, an optimal stationary Markov solution to this problem exists. This solution gives the optimal consumption and retirement decision as a function of $(a, s)$. Appendix A presents the optimizing programs.

\subsection{The French pension system}

The French pension system consists of a wide range of pension schemes. Farmers, civil-servant, wage earners and self-employed people subscribe to different retirement plans. In this paper, we focus on the pension plans of wage earners in private firms. Approximately 70 percent of the labor force falls under this so-called "General Regime".

The benefit that an individual is eligible to receive consists of two elements:

- The first one stems from a "basic general regime" which benefits are based on age, years of contribution to the pension scheme and the employee's lifetime earnings. This regime is based on defined pension plans and managed by a State agency (CNAV). We shall hereafter refer to this regime as "General Regime" (GR).

- The second one is linked to mandatory complementary schemes, organized and managed on an occupational basis (MCSE for executive workers only and MCSNE for non executives). This pension is based on defined contribution plans. We shall hereafter refer to this regime as mandatory complementary schemes for executives (MCSE) and non executives (MCSNE).

Both retirement plans are pay-as-you-go systems. A detailed presentation of the French Social Security provisions can be found appendix B. In the model, rather than relying on calibrated replacement rates, the computation of pensions is based on real - life formulas.

Policy debates as well as this paper focus on how the computation of GR benefits could be modified in order to finance the Social Security deficit generated by the aging of the French population. Depending on the occupational group, 30 to $50 \%$ of the retirement pension is paid by complementary schemes. Obviously, MCSNE and MCSE cannot be discarded when analyzing retirement choices. Besides, the General Regime is directly managed by the government while complementary schemes are managed by trade-unions and representatives of employers. As a 
result, GR and MCSNE along with MCSE are characterized by distinct budgets. In this paper, we will indeed present separate expected deficits as well as the total deficit, in order to measure the impact of Social Security reforms on the total financial stress.

\subsection{Definition of the equilibrium}

Given the vector of prices $(r, w)$, the stationary equilibrium consists of households' choices for consumption, savings and retirement $\left\{c(a, s), a^{\prime}(a, s), \Psi(a, s)\right\}$, value functions $v(a, s)$ and $V(a, s)$, a stationary distribution of households $\lambda(a, s)$ and a set of aggregate variables $\left(A, R^{S S}\right.$, $D^{S S}, R^{M C S N E}, D^{M C S N E}, R^{M C S E}, D^{M C S E}$ ) where $D^{X}$ (respectively $R^{X}$ ) refers to expenditures (respectively the revenues) of the retirement scheme $X$. The stationary equilibrium is such that:

(i) The real interest rate is given, which is consistent with a small open economy hypothesis. This leads to a constant capital to labor ratio, thus making real wages $w$ exogenous.

(ii) Saving decisions $a^{\prime}=g(a, s)$ and retirement behavior $\psi=\Psi(a, s)$ are solutions to the lifetime maximization program where

$$
\Psi(a, s)=\left\{\begin{array}{ll}
1 & \text { if } \\
0 & \text { otherwise }
\end{array}(a,\{s, z\}) \geq v(a,\{R, z\})\right.
$$

for $s=e, u, p$. Finally, let $a^{\prime} \equiv A(a, s)$ be the households' policy that depends on her state on the labor market (employed, pre-retired or unemployed). $A(a, s)$ is such that:

$$
\mathcal{A}(a, s)=\Psi(a, s) g(a, \widehat{s})+[1-\Psi(a, s)] g(a, R)
$$

where an agent's policy in state $\widehat{s}=e, u, p$ is denoted by $a^{\prime} \equiv g(a, \widehat{s})$.

(iii) The new-born's utility $V(a, s)$ is similar to the utility of people who begin working $v(a, s)$.

(iv) The endogenous probability distribution $\lambda(a, s)$ is the stationary distribution associated with $\left(A(a, s), \pi\left(s^{\prime} \mid s\right)\right)$ such that:

$$
\lambda\left(a^{\prime}, s^{\prime}\right)=\sum_{s} \sum_{\left\{a: a^{\prime}=\mathcal{A}(a, s)\right\}} \lambda(a, s) \pi\left(s^{\prime} \mid s\right)^{\prime}
$$

(v) Budget constraints of the general regime (GR) and the complementary schemes (MCSNE and MCSE) are satisfied:

$$
\begin{aligned}
R^{S S}+R_{t r}^{S S} & =D^{S S} \\
R^{M C S N E}+R_{t r}^{M C S N E} & =D^{M C S N E} \\
R^{M C S E}+R_{t r}^{M C S E} & =D^{M C S E}
\end{aligned}
$$

Tax rates endogenously adjust to balance equations (2) to (4). Taxes are paid on wages, unemployment and pre-retirement benefits. Retirees do not contribute to the Social Security budget. Each equation takes into account the transfers paid by unemployment services 
$\left(R_{t r}\right)$ to the GR, MCSE and MCSNE on behalf of unemployed and pre-retired individuals. As a result, periods of inactivity are included in the contributing years to the PAYG system.

(vi) Aggregate financial wealth is given by

$$
A=\sum_{s} \sum_{a} \lambda(a, s) g(a, s)
$$

Given the specification of preferences and the various constraints, it is impossible to find an analytical solution to this equilibrium. We implement numerical techniques based on a discretization of state variables (see Sargent and Ljungqvist [2000] for a detailed presentation of the methodology).

\section{Calibration and quantitative evaluation}

\subsection{Calibration on French data}

This section presents the calibration of the demographic structure, the idiosyncratic labor income risk, the life-cycle profile of labor earnings, the Social Security arrangement and the preferences and technology parameters. Our strategy is to calibrate in order to match selected observations of the French postwar economy. More precisely, we choose to calibrate the model before the French Prime Minister Balladur 1993 reform which plans to progressively modify some key features of the Social Security system. Indeed, the implementation of the reform is gradual so that the full impact of the reform will not be observed before 2008 .

\subsubsection{Technological trend, real interest rate and preferences}

Following Charpin [1999]'s report, the technological trend is set to $2 \%$ a year. The annual real interest rate equals $5 \%$ which corresponds to the average value observed in the last 20 years in France (Artus [1996]). The transformed utility function is :

$$
\frac{c^{1-\sigma}}{1-\sigma} \vartheta(l)=\frac{\left(c^{1-\nu}(1-l)^{\nu}\right)^{1-\tilde{\sigma}}}{1-\tilde{\sigma}}
$$

So, by comparing the two terms of this equation, we have $(1-\nu)(1-\tilde{\sigma})=1-\sigma$. The literature provides values for the risk aversion coefficient $\sigma$. Microdata suggest that $\sigma=2$ (Attanasio, Banks, Meghir and Weber [1999]). Empirical papers implemented on European and US data find that $\sigma$ lies between 1 and 3. We set $\sigma=2$, which also could be interpreted as an average value of these different studies.

Following Castañeda and al. [1998], we impose $1-l=2 / 3$. Unemployed and pre-retired people as well as retirees enjoy full time leisure $(l=0)$. The share of leisure $\nu$, by affecting the willingness to work, is one of the key parameters in the model. However, the observed distribution of retirement ages hardly reveal agents' preferences. Indeed, the current pension system offers little flexibility concerning the choice of retirement age. As underlined by Blanchet and Pelé [1997], "there are strong incentives not to retire at a reduced rate, even if delaying after 60 implies giving up pensions. Finally, after reaching the full rate, we observe [...] a 
heavy tax on work". As a result, in the data, individuals retire as soon as they reach the full rate, which does not allow to pin down the preference for leisure. In order to circumvent this difficulty, we identify an interval of admissible values for this parameter: under a minimum value of preference for leisure, individuals delay retirement beyond their full rate age, while a high value leads to exits before the full rate. We determine these two interval bounds by simulations and set the benchmark value of preference for leisure to the average of the upper and lower bounds. The value of $\nu$ is such that, at the steady state, a unit of good without work is worth 1.71 times a unit of good gotten by working. In other words, the individual would be willing to exchange a unit of good with work with 0.71 unit of good without work. The calibrated value is consistent with Stock and Wise [1990]'s estimate. They indeed found on US data that the ratio of a consumption unit with work to a consumption unit without work equals 1.66. Besides, with the benchmark calibration, the model predicts that $100 \%$ of individuals retire at age 60 . This is consistent with the fact underlined by Blanchet and Pelé [1997] that all individuals retire as soon as they reach the full rate. In addition, based on the 1992 French Labor Force Survey (before the 1993 Balladur reform), this percentage equals $81.6 \%$. As we discard incomplete careers, the model slightly overestimates the peak at age 60 .

The discount factor is set to 0.96. In the benchmark calibration, the altruism is set to $\eta=0.9$, which corresponds to the value chosen to replicate the ratio of bequest to financial asset of $1.4 \%$, as observed in the French data (Arrondel and Laferrère [1996]).

Finally, preferences measure the welfare of one individual. In order to take into account the lifetime family structure, all revenues (wages and pensions) are deflated by "consumption units" (CU). We use information about CUs by age and by social status (INSEE [1999b]) to get table 1.

Table 1: Consumption Units by Social Status and by age

\begin{tabular}{l|cccc}
\hline \hline & $J$ & $A$ & $M$ & $R$ \\
Executives & 1.4000 & 1.8500 & 1.5000 & 1.3000 \\
Middle white collars & 1.4000 & 1.8500 & 1.5000 & 1.3000 \\
Clerks and Blue-Collars & 1.5293 & 2.0209 & 1.6385 & 1.4201 \\
\hline \hline
\end{tabular}

Life expectancy at 60 years old equals 24.4, 20.7 and 18.6 years for executives, middle white collars and blue collars respectively (Charpin [1999]). Blanchet and Monfort [1996] report life expectancy at 65 years old. We infer from this information the decrease in surviving probabilities between these ages, assuming that this decline applies in a similar way to all social groups. Consistent with INSEE [1996], death probabilities reported in table 2 display an exponential pattern with age.

\subsubsection{Wages, employment risks}

Experienced people's wages are higher than younger employees'. The lifetime evolution of wage is the result of this fact (table 3). The data given by INSEE [1999a] are aggregated in order to fit our age structure. Data are extracted from the 1994 database as this is the year for which statistics are close to year 1993, when the Balladur reform was voted. 
Table 2: Death probabilities

\begin{tabular}{lccc}
\hline \hline & & & \\
& Executives & Middle Wh. Collars & Blue collars \\
\hline & & & \\
$1-\pi_{M 59}$ & 0.0333 & 0.0390 & 0.0433 \\
$1-\pi_{M 60}$ & 0.0342 & 0.0403 & 0.0448 \\
$1-\pi_{M 61}$ & 0.0351 & 0.0416 & 0.0464 \\
$1-\pi_{M 62}$ & 0.0361 & 0.0430 & 0.0482 \\
$1-\pi_{M 63}$ & 0.0371 & 0.0444 & 0.0501 \\
$1-\pi_{M 64}$ & 0.0382 & 0.0460 & 0.0521 \\
$1-\pi_{M 65}$ & 0.0394 & 0.0478 & 0.0543 \\
$1-\pi_{M 66}$ & 0.0407 & 0.0496 & 0.0567 \\
$1-\pi_{M 67}$ & 0.0420 & 0.0516 & 0.0593 \\
$1-\pi_{M 68}$ & 0.0434 & 0.0538 & 0.0622 \\
$1-\pi_{M 69}$ & 0.0449 & 0.0561 & 0.0654 \\
$1-\pi_{R R}$ & 0.0466 & 0.0587 & 0.0689 \\
\hline \hline
\end{tabular}

Table 3: Lifetime wages in France (in KF)

\begin{tabular}{c|ccc}
\hline \hline age & -30 & $30-58$ & +59 \\
& & & \\
\hline & & & \\
Executive & 214.79 & 325.79 & 391.71 \\
Midd. Wh. Coll & 140.93 & 186.78 & 225.59 \\
Blue Collars & 100.06 & 124.25 & 126.04 \\
\hline \hline
\end{tabular}


This lead to wage growth factor of 1.24 for clerks and blue collars, 1.33 for middle white collars and 1.52 for executives in the first two periods of life. Between the first and third period of life, wage growth equals 1.26 for clerks and blue collars, 1.6 for middle white collars and 1.83 for executives. In contrast to clerks and blue collars, high skill workers are characterized by a steep wage profile when old.

At the age of 59, agents can loose their job by being either pre-retired or unemployed. The calibration of these events require to know their probability $\left(\pi_{p}\right.$ and $\left.\pi_{u}\right)$ and their consequences on income. Let $\theta_{u}$ and $\theta_{p}$ the replacement ratios associated with unemployment benefits and preretirement income respectively. Table 4 sums up the data taken from Colin, Iéhlé and Mahieu [2000].

Table 4: Employment risks for the elderly

\begin{tabular}{c|cccc}
\hline \hline age & $\theta_{u}$ & $\theta_{p}$ & $\pi_{u}$ & $\pi_{p}$ \\
& & & & \\
\hline Executives & 0.6 & 0.6 & 0.28 & 0.1 \\
Middle White Collars & 0.59 & 0.63 & 0.26 & 0.24 \\
Clerks and Blue Collars & 0.62 & 0.68 & 0.2 & 0.3 \\
\hline \hline
\end{tabular}

In addition, the correlation between the parents' human capital and that of their off-spring is given by the social mobility matrix extracted from INSEE [1995] (table 5).

Table 5: Intergenerational Social Mobility Matrix

\begin{tabular}{lcccc}
\hline \hline & \multicolumn{4}{c}{ Son's Status $(t+1)$} \\
\\
& & & \\
\cline { 2 - 5 } Fathers' Status $(t)$ & Executive & Midd. Wh. Coll. & Blue Collars \\
\cline { 2 - 5 } & Executive & 0.40774 & 0.3187 & 0.27356 \\
& Midd. Wh. Coll. & 0.21912 & 0.35068 & 0.4302 \\
& Blue Collars & 0.092851 & 0.19521 & 0.7119 \\
& & & \\
\hline \hline
\end{tabular}

This matrix implies that $18.31 \%$ of the population consists of executives, $25.79 \%$ belongs to the middle white collars while $55.9 \%$ of the population are clerks and blue collars.

As shown by Colin and al. [2000], the age of end of education differs across categories (table 6). This heterogeneity in the age of end of education has a tremendous impact on retirement choices which are conditional to a minimum duration of contribution. 
Table 6: Age of end of school education

\begin{tabular}{cccc}
\hline \hline & & & \\
& Executives & Midd. Wh. Coll. & Blue Collars \\
\hline$k^{\text {eva }}$ & 22.2 & 19.5 & 17.4 \\
& & & \\
\hline \hline
\end{tabular}

Table 7: Replacement Ratios

\begin{tabular}{ccc}
\hline \hline & Net Wage & \\
in $\%$ & Model (individuals of 60 years old) & Data \\
\hline Executives & 64 & 54 \\
Midd. Wh. Coll. & 76 & 80 \\
Blue Collars & 88 & 92 \\
& & \\
\hline \hline
\end{tabular}

\subsubsection{Social Security}

Appendix B.3 summarizes the calibration on the French pension system. Rather than relying on calibrated replacement rates, the computation of pensions is based on real - life formulas. Figure 1 illustrates the replacement rates predicted by the model under the current retirement rules : individuals who contributed 37.5 years are allowed to a maximum of $50 \%$ of their annual average wage truncated to the Social Security cap and paid by the GR, plus an additional pension from mandatory complementary schemes. The model provides good proxies for replacement ratios (table 7).

Executives, middle white collars and blue collars contribute during the required number of contributive quarters _ 150 under the current system _ at age 60, 57 and 55 respectively. If they retire before contributing 150 quarters, they bear a strong decrease in their pension (figure 1). In addition, should they want to delay retirement, they would get little increase in their pension: only the pension paid by contribution plans, MCSNE and MCSE, adds to the pension in case of continued work. Figure 1 provides a first insight into the constraints inherent to the French retirement provision : retirement provisions entice individuals to retire as soon as they reach the full rate $^{6}$, at age 60,57 and 55 for executives, middle white collars respectively. However, the normal retirement age is fixed to 60 years old in France.

\subsection{Retirement decisions in the nineties}

In order to check the empirical relevance of our model, we present in this section the distribution of retirement age, the dependency ratio and the contribution rates obtained with the benchmark calibration.

\footnotetext{
${ }^{6}$ The age of the full rate is the age when individuals reach 37.5 contributive years.
} 
Figure 1: Replacement rates in the current French pension (150 contributive quarters)

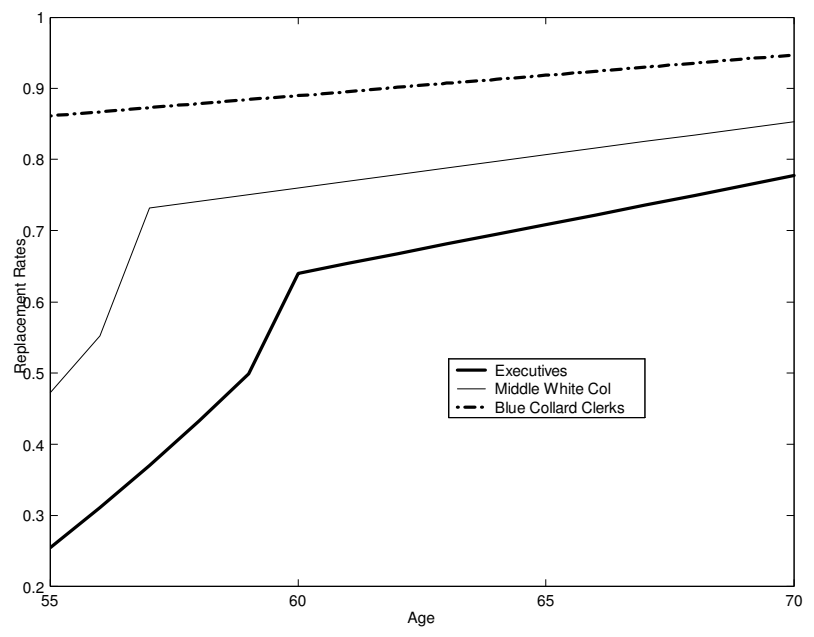

In the benchmark calibration, the model predicts that all individuals retire at age 60 . The normal age of retirement forces blue collars and intermediate professions, who entered the job market at very young ages, to remain at work longer than required by the pay-as-you-go system.

The French hazard rates out of labor force estimated by Blanchet and Pelé [1997] displays much more heterogeneity than in our model with 2 spikes, the first at 60 and the second at 65. The smaller peak at age 65 stems from retirement of incomplete careers and women. In contrast, our model yields a peak only at age 60, which illustrates that our model does not take into account incomplete careers, specific female participation behavior or health status. Indeed, including additional sources of heterogeneity would have made the model less tractable. In spite of the difference in exit rates found by Blanchet and Pelé [1997] and our model, we argue that our framework remains relevant for the purpose of this paper. First, early exits are taken into account in the model since pre-retirement occur at the end of working life. Secondly, we want to show that, in spite of the streamlined heterogeneity, the model is able to generate very heterogeneous retirement ages when incentive schemes are introduced in combination with wealth. Finally, the distribution of hazard rates in Blanchet and Pelé [1997] actually results from a very homogeneous behavior : nearly all individuals retire at the age of their full rate, which is consistent with the agents' behavior in the model.

The dependency ratio equals $43.83 \%$ in the model, which is close to $39 \%$ observed in France today (Charpin [1999]). The model determines the payroll taxes that balance the Social Security budgets. The workers' equilibrium contribution rate to the General Regime equals $8.35 \%$ versus $7.85 \%$ in the data. For complementary schemes (MCSNE and MCSE), the equilibrium rates paid by workers are respectively $3.25 \%$ and $8.63 \%$ in the model versus $2.92 \%$ and $6.96 \%$ in the data (Charpin [1999]). The model develops a stationary equilibrium. As a consequence, we are unable to analyze the effects of baby boomers which refers to a transition issue. This explains why we slightly over-estimate the ratio of retirees to contributors as well as the contribution rates. Hence our calibrated model seems to be able to replicate the main observed features of the French PAYG pension system. 


\section{Retirement behavior and expected Social Security Deficit}

In this section, we assess the impact of the demographic changes on the total Social Security deficit. The Social Security system is then modified to induce the elderly to work longer. The effectiveness of such a reform is assessed. Political debates on Social Security reforms in France focused only on the defined benefit General Regime (GR), as the mandatory complementary schemes (MCSNE and MCSE) are managed by representatives of workers and employers. As a result, we measure in this section what would happen if the pensions paid by the General Regime include incentives to work beyond the full rate. The rules regarding retirement pensions paid by MCSNE and MCSE are left unchanged. Pre-retired and unemployed individuals are not given the incentive plans. In addition, we do not modify the strong penalties associated with early retirement, as we are interested in delaying the retirement age to partially reduce the expected Social Security deficit, and not to restore the global optimality of the system.

\subsection{Taking into account the Balladur 1993 Reform}

Even if the 1993 Reform is not fully implemented yet, we choose to take into account this permanent change in Social Security provisions.

The Balladur 1993 reform mainly lengthens the duration of contribution from 150 quarters to 160 quarters. The model predicts that only executives will delay their retirement since they reach 160 quarters of contribution at the age of 63 (figure 2). Middle and unskilled workers who now reach the full rate at the age of 58 and 60 will not modify their retirement decisions. As in section 3.2, all agents retire as soon as the full rate is reached. Figure 2 displays the cumulative retirement rate in the data (Labor Force Survey, Bac, Bonnet, Bontout and Cornilleau [2000]) and in our model. Because of the gradual implementation of the Balladur reform, the data reveals the impact of only half of the lengthening of contributive quarters. However, the Labor Force Survey suggests that some individuals start delaying retirement. The model matches the early exit (due to pre-retirement), the spike at 60 and, to a lesser extent, the smaller peak at 63. Again, since we discard heterogeneity in health status, specific female participation and incomplete careers, the model cannot capture the complete distribution of retirement age. However, figure 2 indicates that our theoretical framework provides a reasonable proxy for the current retirement behavior.

Finally, since only $18 \%$ of the population are executives, the lengthening of working period of high skilled workers slightly improves the dependency ratio : the latter declines to $41.81 \%$, which leads to a decrease in the workers' equilibrium contribution rate to the General Regime $(7.8 \%)$ and to complementary schemes (3.2\% for MCSNE and $8.45 \%$ for MCSE). Finally, figure 2 suggests that only a reform that puts off the retirement age of unskilled workers (who constitutes $50 \%$ of the labor force) may significantly improve the dependency ratio.

To grasp the intuition behind the distribution of retirement age, figure 3 plots the replacement rates computed after the Balladur Reform : with the lengthening of contributive quarters, replacement rates shift to the right. The structure of GR provisions is not modified:

- before the age of the full rate, individuals bear a strong decrease in pensions.

- after the age of the full rate, the increase in the pension is weak in case of continued work 
Figure 2: Cumulative retirement eate by age

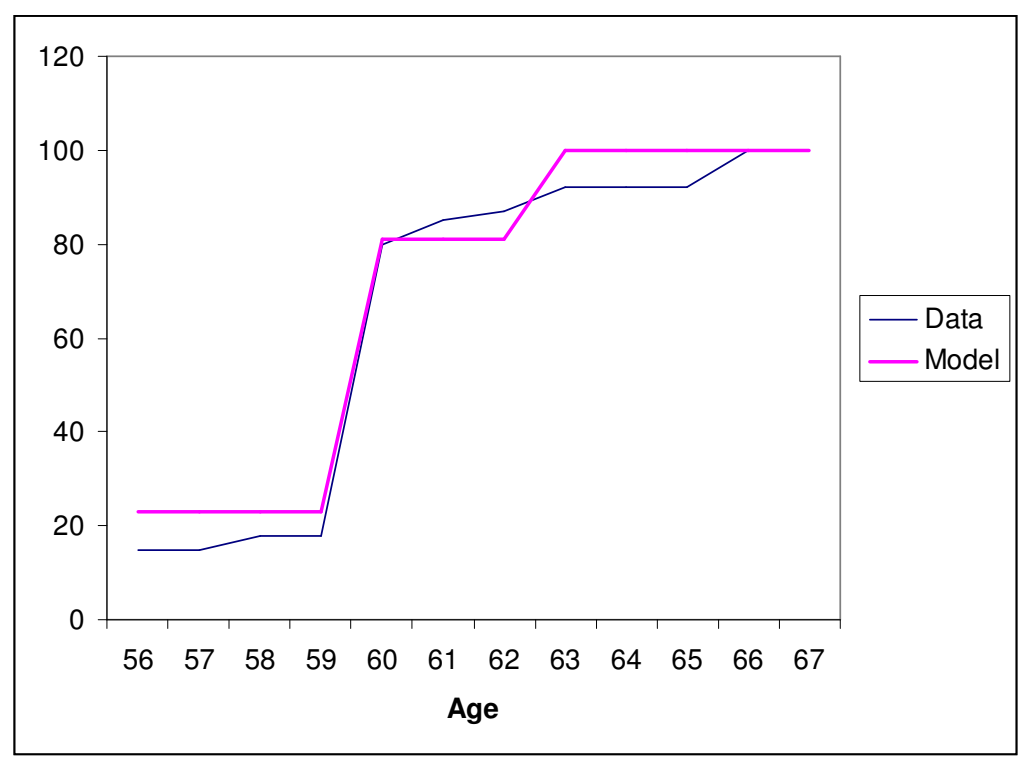

Figure 3: Replacement rates after the Balladur Reform (160 contributive quarters)

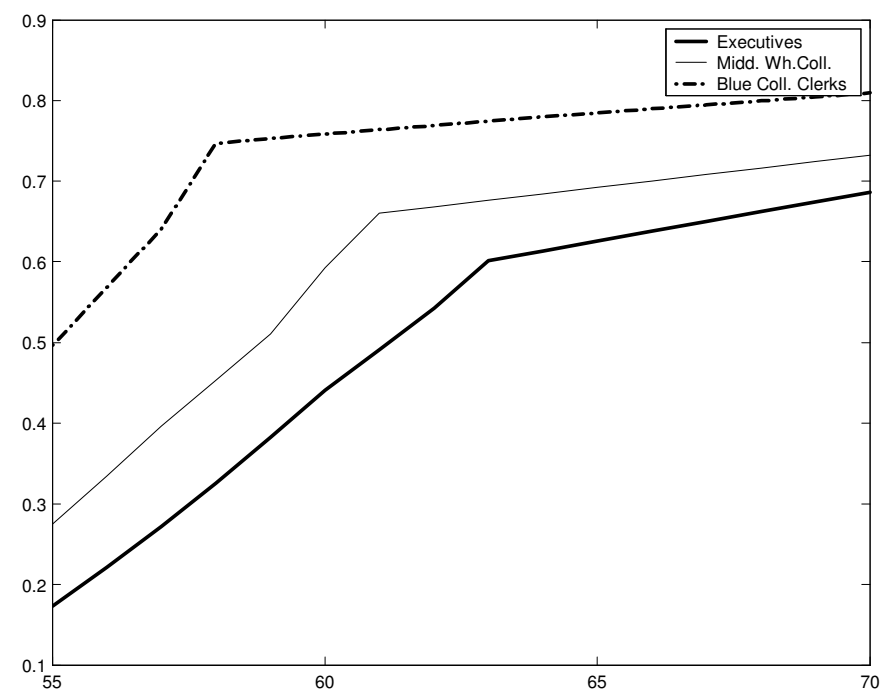


Table 8: Marginal Tax on Continued Work after the Balladur reform (in \%)

\begin{tabular}{lcccccccccc}
\hline \hline & \multicolumn{8}{c}{ General Regime - GR } \\
Age & 60 & 61 & 62 & 63 & 64 & 65 & 66 & 67 & 68 & 69 \\
\hline Executives & 11.01 & 14.4 & 40.86 & 47.23 & 47.44 & 47.57 & 47.69 & 47.82 & 47.96 & 48.09 \\
Midd. Wh. Coll. & 69.82 & 70.04 & 70.27 & 70.50 & 70.74 & 70.98 & 71.23 & 71.48 & 71.74 & 72.00 \\
Blue Coll. & 93.91 & 94.32 & 94.73 & 95.15 & 95.98 & 96.35 & 96.74 & 97.13 & 97.53 & 97.94 \\
\hline \hline \multicolumn{8}{c}{ Mandatory Complementary Schemes - MCSNE+MCSE } \\
Age & 60 & 61 & 62 & 63 & 64 & 65 & 66 & 67 & 68 & 69 \\
\hline Executives & 13.40 & 15.78 & 18.35 & 39.2 & 41.1 & 43.1 & 45.1 & 47.1 & 49.1 & 51.2 \\
Midd. Wh. Coll. & 21.9 & 23.1 & 24.4 & 25.6 & 26.9 & 28.2 & 29.5 & 30.9 & 32.2 & 33.6 \\
Blue Coll. & 24.0 & 24.9 & 25.8 & 26.8 & 27.7 & 28.7 & 29.7 & 30.6 & 31.7 & 32.7 \\
\hline \hline
\end{tabular}

Furthermore, we compute the marginal tax on continued work denoted $\tau_{\text {marginal }}$. If an individual decides to postpone his retirement by one year, his pension level will not adjust so as to compensate for the additional payroll tax he pays (explicit tax) and for the fact that he receives pension benefits for one fewer year (implicit tax). Let us define

$$
\tau_{\text {marginal }}(z)=\frac{\left(\sum_{i=0}^{T(z)} \frac{P_{z}}{(1+r)^{i}}-\Pi_{z z+1} \sum_{i=1}^{T(z+1)} \frac{P_{z+1}}{(1+r)^{i}}\right)+\theta w(z)}{w(z)}
$$

where $\tau_{\text {marginal }}(z)$ is the marginal tax on continued work for an individual of age $z, P_{z+1}$ the pension when retirement occurs at age $z+1, \Pi_{z z+1}$ the survival probability between age $z$ and $z+1, T(z)$ life expectancy at age $z, \theta$ the payroll tax and $w(z)$ earnings at age $z, r$ the rate of return on financial markets. Table 8 reports the values obtained for the current Social Security provisions. The taxes are computed for years beyond the minimal retirement age (60 years old).

In the General Regime, beyond the age of the full rate, the tax on continued work is large, in particular for blue collars and middle white collars who experience a lower life expectancy than executives. In addition, the tax on continued work is lower for complementary schemes since they are based on defined contribution plans. Before the full rate, as the retirement pension increases with age, the tax is lower than the contributive rate.

In this paper, we modify the incentives controlled by the government, namely retirement provisions paid by the General Regime. The implicit tax of complementary schemes is left unchanged. This implies that, when individuals delay retirement, MCSNE and MCSE experience an improvement in their budget deficit.

\subsection{Expected Social Security deficit}

From now on, taking into account the 1993 Reform, we keep all the parameters of the model constant. Only the transition matrix describing the population dynamics and the Social Security program are modified.

Following the predicted evolution of the French population, we assume that there will be an increase in life expectancy: in year 2040, the life expectancy at age 60 is expected to go up by 6 years. For want of further information about the expected mortality risk across social groups in 2040, we finally assume that the increase in life expectancy applies homogeneously to all 
occupational categories. The increase in the number of retirees is then explained by the increase in life expectancy, thereby discarding the effect of baby boomers on the dependency ratio.

The dependency ratio as predicted by the model equals 56.6\%. The French estimates hover around $60 \%$. The model predicts that the modification in the demographic environment does not affect the distribution of retirement age that mimics figure 2. Even if they expect a longer life, individuals still decide to retire as soon as they reach the full rate. However, asset holding increases significantly : individuals save more in order to insure themselves from the risk of outliving their assets. Without any Social Security reform, the increase in life expectancy is not significant enough to make them willing to work longer.

Furthermore, holding all payroll rates constant, demographic changes, by deteriorating the dependency ratio, generate deficits of the General regime (GR) and the complementary plans (MCSNE and MCSE). Approximately 29\% of the total pensions are not financed in 2040, which is consistent with French official estimates (COR [2001]). Social security reforms may reduce this alarming percentage. The following sections measure the ability of incentive schemes to finance the expected deficit.

\subsection{Actuarially Fair Scheme and Retirement Behavior}

We first analyze the incidence of actuarially fair incentives on retirement behavior and on the total expected Social Security deficit as well as the strong interaction between this policy and the wealth accumulation process.

\subsubsection{Definition of the actuarially fair scheme}

Let $\lambda_{2}^{*}(z)$ be the actuarially fair adjustment given to an individual of age $z$ who is willing to work beyond the required 40 years of contribution. As long as the individual has not contributed long enough to reach the full rate, $\lambda_{2}^{*}(z)=0$. The actuarially fair scheme is defined only on the State benefits (paid by the basic regime). Complementary schemes, managed by trade unions, are left unchanged as they are not the focus of public debate.

Let us consider an individual of age $z$ who faces two choices: either he claims Social Security benefits now and receives his pension until his expected date of death or he continues working and retires at age $z+1$, knowing that life expectancy is lower at age $z+1$. The actuarially fair adjustment $\lambda_{2}^{*}(z)$ is such that both options are neutral for the Social Security budget:

$$
\Pi_{z z+1} \sum_{i=1}^{T(z+1)} \frac{\left(\lambda_{2}^{*}(z+1)+0.5\right) w^{r e f}(z+1)}{(1+\tilde{r})^{i}}-\theta w(z)=\sum_{i=0}^{T(z)} \frac{\left(\lambda_{2}^{*}(z)+0.5\right) w^{r e f}(z)}{(1+\tilde{r})^{i}}
$$

where $w^{r e f}(z+1)$ denotes the life-time average wage and $\tilde{r}$ the actualization rate. $\lambda_{2}^{*}(z)$ is such that the postponement of retirement from age $z$ to age $z+1$ is neutral for the Social Security budget. Equation (5) states that the pensions paid by the Social Security if the individual retires at age $z+1$ minus the contributions collected on wages earned during year $z$ equals the pensions paid in case of retirement at age $z$.

Equation (5) implies that, as the individual grows older, he has to be given an increasing actuarially fair adjustment to make him work longer. Indeed, the actuarially fair adjustment has to compensate the worker for the increasing probability of death. In table 9 , for a given 
Table 9: Actuarially Fair Scheme

\begin{tabular}{lccccccccc}
\hline$\tilde{r}=0 \%$ & \multicolumn{8}{c}{$\lambda_{2}^{*}(z+1)-\lambda_{2}^{*}(z)$} \\
\hline Age $z+1$ & 61 & 62 & 63 & 64 & 65 & 66 & 67 & 68 & 69 \\
\hline Executives & 0 & 0 & 3.35 & 3.61 & 3.92 & 4.26 & 4.63 & 5.04 & 5.51 \\
Middle White Collars & 3.58 & 3.9 & 4.26 & 4.66 & 5.12 & 5.62 & 6.2 & 6.86 & 7.61 \\
Blue Collars. Clerks & 3.75 & 4.12 & 4.52 & 5.04 & 5.58 & 6.2 & 6.9 & 7.72 & 8.66 \\
\hline \hline
\end{tabular}

occupational group, executives for instance, the increase in the marginal adjustment $\left(\lambda_{2}^{*}(z+1)\right.$ $-\lambda_{2}^{*}(z)$ ), as the individual grows older, mirrors the decrease in life expectancy. Moreover, actuarially fair adjustments mimic the inequality in life expectancies across occupational groups : at all ages, blue collars and clerks who experience a lower life expectancy than executives receive a higher incentives than high skilled workers.

Furthermore, the computation of the actuarially fair adjustment is based on an actualization interest rate $\tilde{r}$. In the benchmark scenario, only one interest rate is considered : from a public finance stance, the return on the PAYG system is the relevant one. As the productivity efficiency gains are already incorporated into the reference wage $w^{r e f}$, it remains the population growth rate. Since in our setting the population remains constant, we impose $\tilde{r}=0 \%$. The General Regime immediately shares the additional surpluses among the current generation of retirees. In a steady state equilibrium, the probabilities in equation (5), when taken over the whole population, give the proportion of retirees still alive who are likely to benefit from the incentive scheme.

Figure 4 illustrates how the introduction of the actuarially fair scheme affect replacement rates. After the Balladur reform, individuals are required to contribute 160 quarters to the GR before being entitled to a maximum of $50 \%$ of their average wage. Executives, middle white collars and blue collars meet this condition at age 63, 60 and 58 respectively. Since the actuarially fair scheme only applies to continued work, the strong penalties in case of early retirement are not modified. In contrast to figures 1 and 3 , in case of delayed retirement, workers get a significant increase in replacement rates as they age, since the additional pension compensates them for the decrease in their life expectancy. Section 4.3.2 measures the impact of these modified retirement provisions on retirement behavior.

\subsubsection{Impact of the actuarially fair scheme on retirement behavior}

What happens when individuals are given the actuarially fair rate? All categories of employed workers postpone their retirement (figure 5). An actuarially fair rate does entice workers to delay their retirement. In contrast, pre-retired and unemployed, who do not benefit from the incentive schemes, do not postpone retirement. The dependency ratio declines from $60 \%$ to $50 \%$. By definition, if individuals are given the actuarially fair adjustment, it does not help finance the expected General Regime deficit. In contrast, complementary schemes based on defined contribution plans (MCSNE and MCSE) benefit from the fact that workers do defer their retirement. The total reduction in expected deficit then equals $10.4 \%$. However, as the public regime is the main part of the expected deficit, actuarially fair incentives may not be the best way to reduce the total deficit. Moreover, there is no compensation between the different regimes: the incentives in the public regime must be determined in order to minimize its expected 
Figure 4: Replacement rates with actuarially fair scheme (160 contributive quarters)

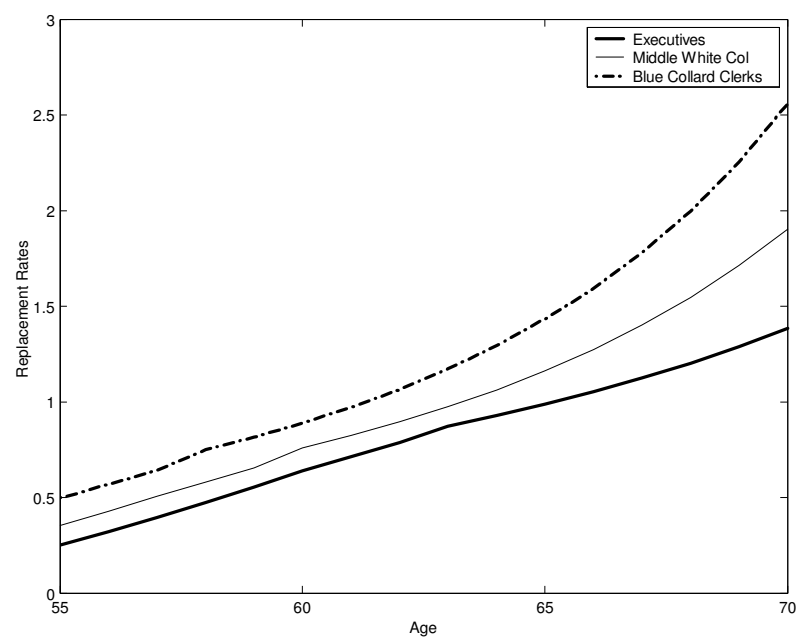

deficit.

Executives and middle white collars cease to work on average at the age of $67-68$ and blue collars at 63 (Figure 5). However, in all categories, some retirements occur before these peaks. It then appears some heterogeneity in retirement choices both across and within social categories, but also across the labor market status.

\subsubsection{Multidimensional Heterogeneities}

The heterogeneity across individuals of different labor status is the easiest to explain. As preretired and unemployed people do not receive any incentives, they keep on claiming Social Security provisions at their full rate age.

The heterogeneity across social categories is more subtle and illustrates the two opposite effect of wealth on retirement age. The first effect is illustrated in figure 6 that reports value functions of an executive of 63 years old who considers retirement the following year. In order to make up his mind, he compares the value function of a person who retires at age 64 to that of a worker of 64 years old. The value functions intersect when his financial holding equals $A^{*}=24.16$. If his current wealth is larger than $A^{*}$, the executive would rather retire the following year. If the executive is not rich enough $\left(A<A^{*}\right)$ today, he chooses to keep on working next year. The model actually yields an array of wealth thresholds above which individuals of each social category decide to retire. Table 10 reports these thresholds for each retirement age (first column) and each social group. For instance, blue collars of 59 years old who consider retiring next year must have a current wealth larger than 9.42 in order to cease working at age 60 .

$A^{*}$ is systematically the highest for executives and the weakest for blue collars. What does it mean? Executives are the most willing to work longer. Their wage is high relatively to their pension (their replacement ratio is the lowest) and to the expected wage of their children, given the social mobility. This is not the case for blue collars, and, to a lesser extent, for middle white collars. It must be noticed that the reference to the expected wage of their children hugely depends on the altruism and the social mobility considered in the model. The combination of 
Figure 5: Distribution of retirement age when individuals are given the actuarially fair scheme $(\tilde{r}=0 \%)$
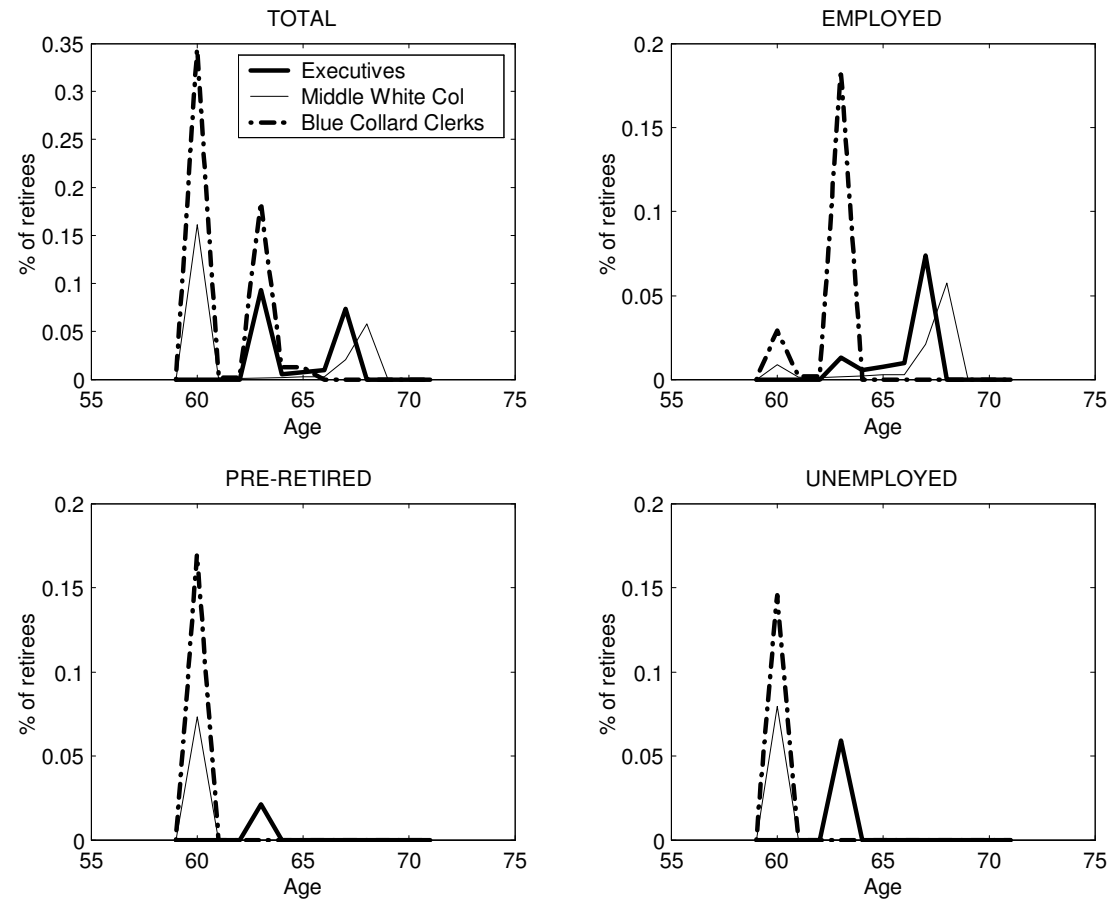

Table 10: Wealth Threshold in Retirement Decision Rules $A^{*}$

\begin{tabular}{cccc}
\hline \hline Age & Executives & Middle Wh. Coll. & Blue Coll. and Clerks \\
\hline 60 & 165.99 & 27.00 & 9.42 \\
61 & 165.99 & 24.04 & 7.87 \\
62 & 165.99 & 21.73 & 6.53 \\
63 & 29.03 & 18.87 & 0 \\
64 & 24.16 & 15.91 & 0 \\
65 & 18.87 & 12.31 & 0 \\
66 & 13.87 & 9.04 & 0 \\
67 & 5.79 & 1.24 & 0 \\
68 & 2.87 & 0 & 0 \\
69 & 0 & 0 & 0 \\
70 & 0 & 0 & 0 \\
\hline \hline
\end{tabular}


Figure 6: Value Function of Executives of 64 years old

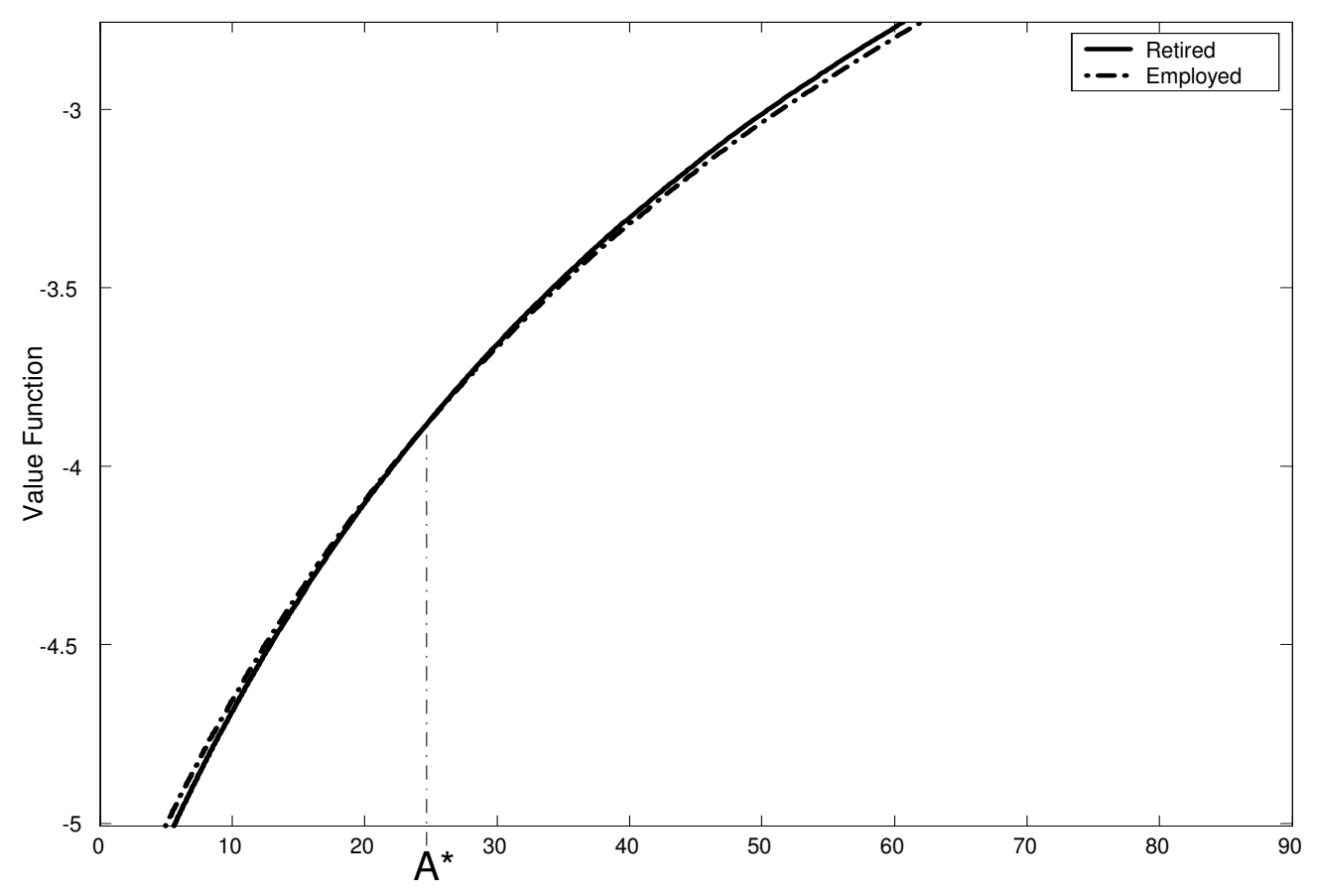


wages earned when employed associated with higher pensions when retired allows the individual to accumulate assets. This desire to save stems from her concern for the welfare of her off-spring. Inherited capital constitutes an insurance against bad luck in the drawing of social status at the beginning of life. This fear for children's future is particularly keen for executives whose off-springs bear the risk of a deterioration of their social status. The desire to accumulate asset make executives postpone retirement.

However, to fully understand the retirement age across social categories, it is necessary to consider the wealth distribution. The second effect of wealth tends to bring forward retirement. As can be seen on figure 5, despite an inferior threshold, some middle white collars delay more their retirement than some executives because they are less wealthy. As the threshold of blue collars is weak, their financial asset level, even if this latter is inferior to the other social categories one, allows them to retire before 63 . The impact of wealth on retirement decision tends to bring forward the retirement date.

Heterogeneity within each social group mirrors wealth heterogeneity. The wealthiest are not responsive to incentives. This effect appears for instance on figure 5: blue collars' retirement age spans from 60 to 63 . The unskilled workers who retire before 63 inherited a substantial wealth from their parents who belonged to higher social categories. They benefited from the precautionary savings of their parents: inherited savings then do insure the off-spring against the risk of being born in a lower social group. They are thus rich enough to discard the incentive scheme. This feature is exacerbated in the case of middle white collars whose retirement age spans from 60 to 68 . Similarly, some executives belonging to a dynasty of executives are wealthy enough to completely disregard incentives and to retire at the age of their full rate (63 years old). The social mobility explains the wealth heterogeneity across agents belonging to the same social class.

\section{The Laffer curve}

This section aims at assessing the incentive schemes which could minimize the public Social Security expected deficit.

\subsection{Pure PAYG pension system and optimized incentives}

Individuals now receive a fraction $(1-\tau)$ of the actuarially fair scheme. Table 11 displays the impact of these different schemes on the expected public Social Security deficit.

Column (1) that reports the impact of actuarially fair schemes on the GR expected deficit captures a first Laffer curve. With low values of $\tau$, individuals have a strong incentive to delay retirement decision. However, the incentives are close to the actuarially fair value, which is, by definition, neutral for the GR deficit. In contrast, high values of $\tau$ increase the contributions collected by the GR. Nevertheless, employees are given only a small incentive to work beyond the full rate. With $\tau=0.7$, all social groups retire as soon as they reach the full rate : the distribution of retirement age mimics figure 2. Individuals do not respond to incentives. The change in Social Security provisions does not improve the expected budget deficit.

The Laffer curve yields an incentive rate $\tau^{*}$ that maximizes the reduction in the GR deficit. Table 11 suggests $\tau^{*}=0.3$ that leads to a $8.7 \%$ decrease in the expected deficit. The associated distribution of retirement age is displayed in the upper panel of figure 7 . 
Table 11: Actuarially fair incentives and SS deficit $(\tilde{r}=0 \%)$

\begin{tabular}{|c|c|c|c|c|c|}
\hline \multirow[b]{2}{*}{$\tau$} & \multicolumn{5}{|c|}{ Expected decline in Social Security Deficit (\%) } \\
\hline & $\begin{array}{l}\text { GR } \\
(1)\end{array}$ & $\begin{array}{c}\text { MCSNE } \\
(2)\end{array}$ & $\begin{array}{c}\text { MCSE } \\
(3)\end{array}$ & $\begin{array}{c}\text { Total } \\
(4)\end{array}$ & $\begin{array}{c}\text { Dependency } \\
\text { ratio }\end{array}$ \\
\hline 0 & 0.0 & -30.0 & -23.1 & -10.4 & 50.0 \\
\hline 0.1 & -5.2 & -24.8 & -21.7 & -12.2 & 51.1 \\
\hline 0.2 & -7.5 & -18.5 & -18.8 & -11.7 & 52.9 \\
\hline 0.3 & -8.7 & -14.4 & -14.2 & -10.8 & 53.7 \\
\hline 0.4 & -8.0 & -9.5 & -9.2 & -8.5 & 54.6 \\
\hline 0.5 & -6.4 & -6.1 & -4.3 & -6.1 & 55.3 \\
\hline 0.6 & -2.9 & -2.1 & -2.5 & -2.6 & 56.1 \\
\hline 0.7 & 0 & 0 & 0 & 0 & 56.6 \\
\hline
\end{tabular}

Recall that GR is the General Regime based on defined pension plans. MCSNE and MCSE are mandatory complementary schemes based on defined contribution plans. Figures in columns (1) to (4) are changes in each deficit. The benchmark SS deficit is the one computed for year 2040 without SS reforms

A second Laffer curve appears when we consider the total change in Social Security deficit (column (4) of table 11). The maximum point of this second Laffer curve is actually $\tau^{*}=$ 0.1 with a $12 \%$ decrease in the total Social Security deficit. With a lower tax on continued work ( $\tau$ decreases), as more individuals delay retirement, the deficit of both contribution-based complementary schemes declines. The combination of the first Laffer curve and the growing fall in MCSNE and MCSE deficit yields the second Laffer curve. The subsequent retirement age across social groups is displayed in the lower panel of figure 7 .

If Social Security benefits were more flexible, individuals are expected to take advantage of incentive schemes. It appears that wealth plays a key role in retirement decisions. Indeed, the distribution of retirement age is more spread out, which mirrors wealth heterogeneity. On figure 7 , for instance, the wealthiest employed executives retire earlier, the others accept to postpone retirement either to get an increased pension when they retire or to increase their saving in order to insure their off-spring against bad luck in the random drawing of social status at the beginning of life. Given the high degree of altruism in the model, the effect of the incentive scheme is weak. As a result, the maximum of the Laffer curve is reached for a low value of $\tau$, the expected reduction in Social Security deficit does not top $12 \%$. As shown by figure 8 , lower altruism yields more significant decrease in the total Social Security deficit. The high value of altruism considered in the benchmark calibration (in order to match the French ratio of bequest over financial holding) penalizes the efficiency of incentive schemes.

Social mobility via the bequest motive seems to play a crucial role in the different kinds of heterogeneity in retirement age generated by incentive schemes. The role of this wealth 
Figure 7: Distribution of retirement age of employed individuals $(\tilde{r}=0 \%)$
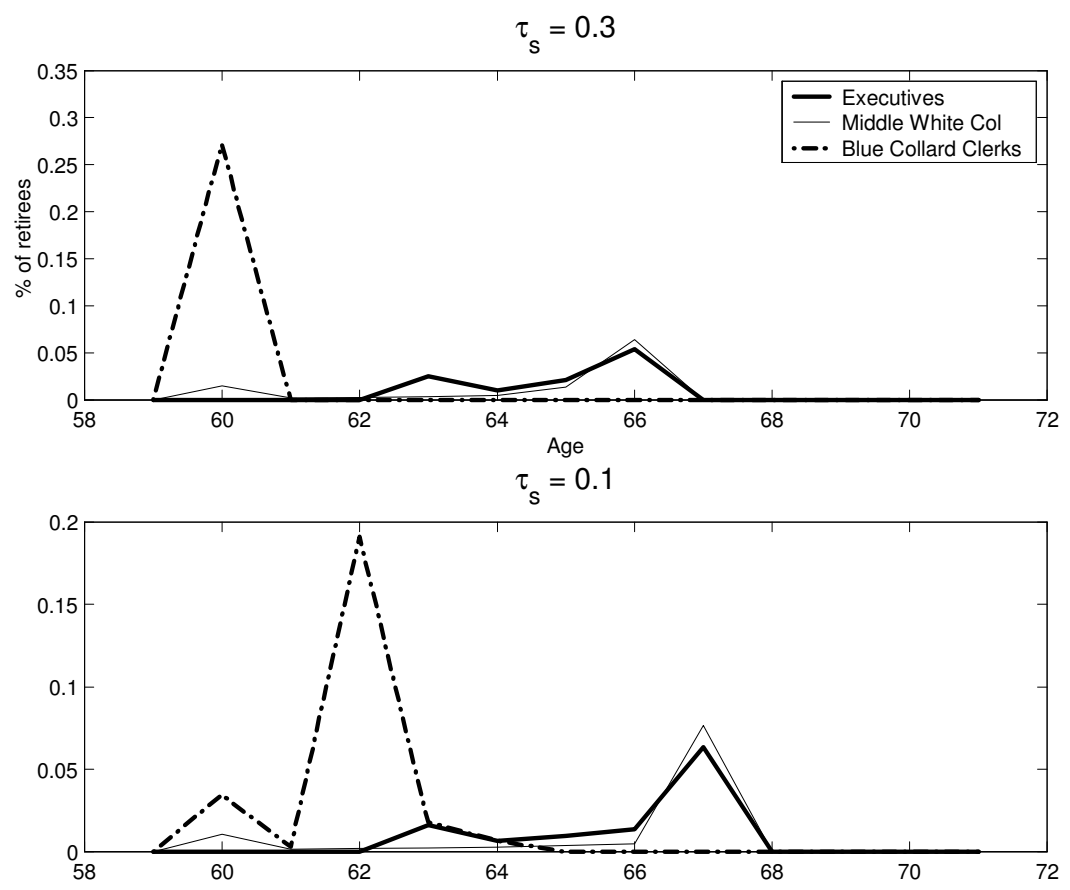

Figure 8: Expected reduction in total SS deficit as a function of altruism $(\eta)$

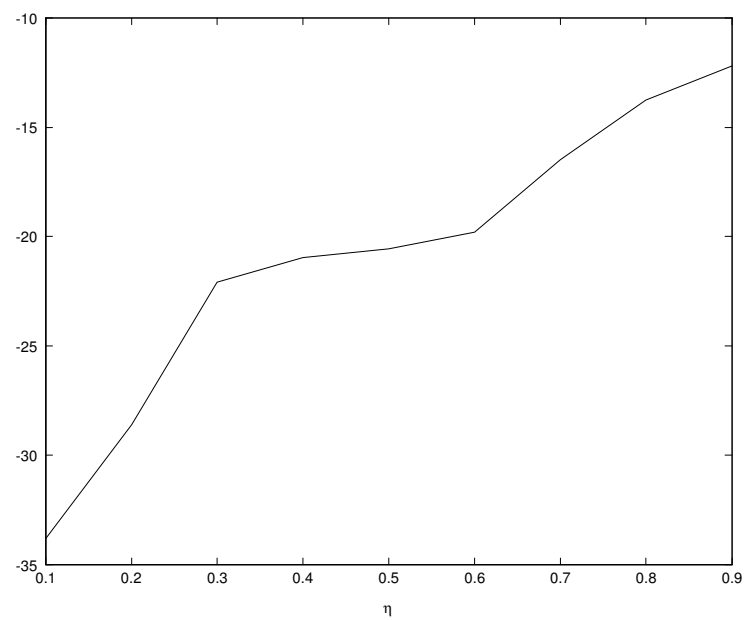


Table 12: Laffer Curve when unemployment and pre-retirement rates are lower

\begin{tabular}{ccccc}
\hline \hline$\tau$ & \multicolumn{2}{c}{ Benchmark } & \multicolumn{2}{c}{ Higher LFPR } \\
& Total change in SS deficit & Dependency Ratio & Total change in SS deficit & Dependency Ratio \\
\hline & & & & \\
0 & -10.4 & 50.0 & -13.5 & 45.8 \\
0.1 & -12.2 & 51.1 & -16.3 & 47.7 \\
0.2 & -11.7 & 52.9 & -15.3 & 50.6 \\
0.3 & -10.8 & 53.7 & -14.0 & 52.0 \\
0.4 & -8.5 & 54.6 & -10.5 & 53.4 \\
0.5 & -6.1 & 55.3 & -6.8 & 54.5 \\
0.6 & -2.6 & 56.1 & -1.2 & 55.8 \\
& & & \\
\hline \hline
\end{tabular}

effect can be de-emphasized by examining a change in the degree of altruism $(\eta)$. As altruism decreases, individuals reduce their savings for bequests motive, which results in a steady fall in the asset holding to income ratio. First, as individuals decrease their savings for bequest motives, we observe less heterogeneity within each social group. Furthermore, it is noticeable that when individuals care less about their children, they are likely to work longer. With the fall in bequest, individuals are not rich enough to retire early. This last point also indicates that the benchmark calibration constitutes the worst case scenario for our incentive schemes.

Finally, in the benchmark scenario, the impact of incentives might appear weak. Nevertheless, official estimates (COR [2001]) forecast a decline in unemployment and pre-retirement rates for old workers. The larger the labor force participation rate (LFPR), the greater the impact of incentive schemes on the Social Security deficit. As all experts disagree about the magnitude of the phenomenon, we consider a more favorable hypothesis on the labor market : the unemployment and pre-retirement probabilities are divided by 4 , consistently with a middle scenario in official estimates. As shown by table 12, the Laffer curve shifts up : the effectiveness of incentive schemes is larger, we reach a decline of the total Social Security deficit of $16 \%$, instead of $12 \%$ in the benchmark scenario. Furthermore, the dependency ratio amounts to $47 \%$ instead of $51 \%$. However, as $\tau^{*}$ remains low $\left(\tau^{*}=10 \%\right)$, the total reduction in Social Security deficit does not top $16 \%$.

\subsection{Incentives and financial proceedings}

In order to improve the efficiency of incentive schemes, we propose to introduce a careful "portfolio management at the margin" into the PAYG system. Such a reform combined with the incentive programs does not modify the intergenerational solidarity inherent to the PAYG system.

With incentive schemes described in the last section, when someone delays retirement, the General Regime immediately shares the additional taxes among the current generation of retirees. Alternatively, the GR could invest the additional receipts (collected taxes on wages and pension not paid to workers who delay retirement) on the financial markets on risk-free bonds which return is $\tilde{r}>0$. The return on financial investment helps finance the increase in the GR pension of the individuals who accepted to defer retirement. This corresponds to a mandatory 
Table 13: Actuarially fair Incentives

\begin{tabular}{lccccccccc}
\hline \hline$\tilde{r}=5 \%$ & \multicolumn{8}{c}{$\lambda_{2}^{*}(z+1)-\lambda_{2}^{*}(z)$} \\
\hline$z+1$ & 61 & 62 & 63 & 64 & 65 & 66 & 67 & 68 & 69 \\
\hline Executives & 0 & 0 & 5.85 & 6.48 & 7.19 & 7.98 & 8.89 & 9.91 & 11.08 \\
Middle White Collars & 6.14 & 6.85 & 7.65 & 8.56 & 9.6 & 10.81 & 12.19 & 13.8 & 15.65 \\
Blue Collars. Clerks & 6.18 & 6.94 & 7.81 & 8.86 & 10.03 & 11.39 & 12.97 & 14.83 & 17.02 \\
\hline \hline
\end{tabular}

funded GR system at the margin by which the GR has access to a higher rate of return.

This section measures the sensitivity of our results to the rate of return considered. As can be seen from table 13, with a higher interest rate $(\tilde{r}=5 \%)$, incentives increase: as GR collects financial returns, the General Regime (GR) can increase the incentives to work beyond the full rate.

The Laffer curve presented in table 14, column (4), reaches an optimum with $\tau^{*}=0.4$ : with a return on financial investment, the Social Security grants a lower fraction of the actuarially fair scheme in order to entice individuals to delay retirement. In addition, the maximum decline in the total expected Social Security deficit amounts to $-30 \%$ versus $-12 \%$ when $\tilde{r}=0 \%$.

Table 14: Actuarially fair incentives and SS deficit $(\tilde{r}=5 \%)$

\begin{tabular}{l|ccccc}
\hline \hline & \multicolumn{5}{|c}{ Expected Decline in Social Security deficit (\%) } \\
& GR & MCSNE & MCSE & Total & Dependency \\
$\tau$ & $(1)$ & $(2)$ & $(3)$ & $(4)$ & Ratio \\
\hline & & & & & \\
0 & 0 & -49.9 & -40.7 & -17.7 & 45.6 \\
0.1 & -8.6 & -49.2 & -39.9 & -22.7 & 45.7 \\
0.2 & -16.2 & -46.1 & -38.8 & -26.5 & 46.4 \\
0.3 & -22.3 & -42.4 & -36.9 & -29.2 & 47.3 \\
0.4 & -26.4 & -37.8 & -34.0 & -30.2 & 48.3 \\
0.5 & -21.9 & -26.4 & -22.2 & -23.0 & 51.3 \\
0.6 & -16.8 & -16.9 & -15.0 & -16.6 & 53.3 \\
0.7 & -10.7 & -8.7 & -8.1 & -9.8 & 54.8 \\
& & & & & \\
\hline \hline
\end{tabular}

Recall that GR is the General Regime based on defined pension plans. MCSNE and MCSE are mandatory complementary schemes based on defined contribution plans. Figures in columns (1) to (4) are changes in each deficit. The benchmark SS deficit is the one computed for year 2040 without SS reforms

Figure 9 displays the distribution of retirement choices for the maximum point of the Laffer curve. Due to larger incentives, unskilled workers, who represent $50 \%$ of the labor force, significantly delay retirement until the age of 65 versus 63 on figure 7 .

Incentive schemes along with this portfolio management at the margin could indeed substantially help fund the expected Social Security deficit while preserving the intergenerational solidarity of the PAYG system. 
Figure 9: Distribution of retirement age of employed individuals at the maximum point of the Laffer Curve, $\tau=0.4(\tilde{r}=5 \%)$

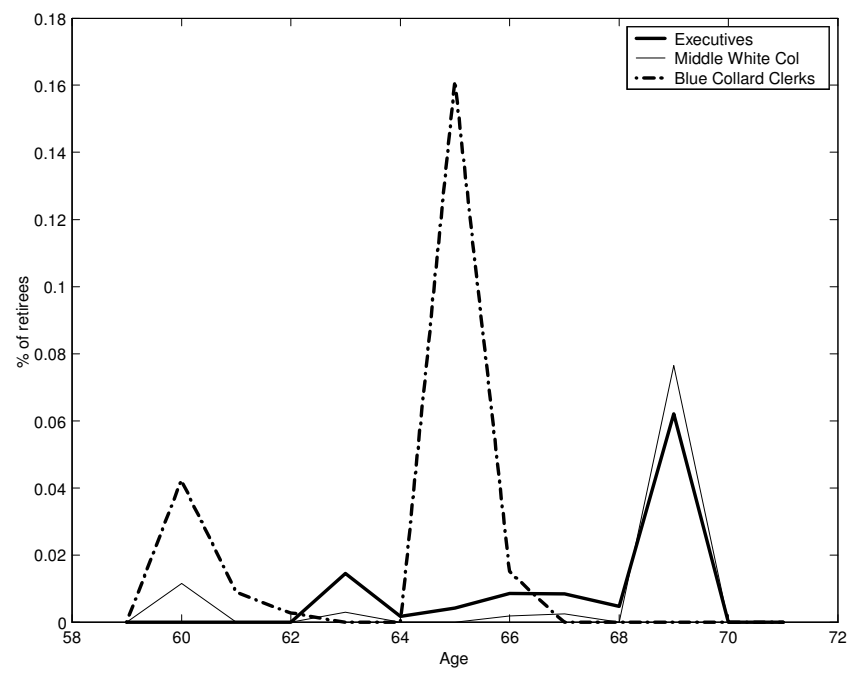

\section{Conclusion}

Our quantitative exercise relies on French data since France exemplifies a PAYG system in which there is little choice in the retirement decisions. Incentive program introduces a contributive flavor in the French defined pension plan. We find that individuals are responsive to incentive programs: all social groups accept to postpone retirement providing they are given enough incentives. The Social Security faces a trade off between giving enough incentives to make individuals actually put off retirement and giving little increase in Social Security provisions in order to help finance the expected deficit of the PAYG system. This trade-off is captured by a Laffer curve.

We show that, once incentives allowing to bring retirement decisions closer to the optimum are taken into account, the interplay between wealth and the elderly's labor participation becomes stronger. It is then crucial to carefully model wealth accumulation motives in order to gauge the effect of the lengthening of retirement age. In this paper, we particularly focus on the altruism motive in presence of intergenerational social mobility and borrowing constraints. It appears that high degrees of altruism along with social mobility penalize the efficiency of incentive schemes. Finally, in order to enhance the ability of incentive programs to finance the expected Social Security deficit, the additional taxes collected in case of delayed retirement should be invested on the financial market. In the most favorable scenario, up to $30 \%$ of the expected deficit is financed through incentives.

We assumed in the paper that the General Regime of the Social Security is facing a surviving probability captured by the average mortality observed in the population. However, it is fairly intuitive that individuals who consider themselves in a better health condition are enticed to delay retirement, which could increase the surviving probability of workers who actually postpone retirement. As a result, there would be a risk of deepening the Social Security deficit. In order to take into account this adverse selection phenomenon, one should implement incentive 
schemes that remedy this asymmetric information issue. This is left for future research.

\section{Appendix}

\section{A Optimizing programs}

Decision rules are solution to the following optimizing programs

1. Choice when young $(s \in J)$

At the beginning of her life cycle, choices are limited to the choice of optimal savings that solve the following program

$$
\begin{aligned}
v(a, J) & =\max _{c \geq 0} u(c, l)+\tilde{\beta}\left\{\pi_{J J} v\left(a^{\prime}, J\right)+\left(1-\pi_{J J}\right) v\left(a^{\prime}, A\right)\right\} \\
(1+g) a^{\prime} & =(1+r) a+w(J)-\Theta(w(J))-c \\
a^{\prime} & \geq 0
\end{aligned}
$$

where $v$ denotes the household's value function, $r$ and $w$ the interest rate and the wage. Finally, $\Theta(w(J))$ embodies taxes used to finance the pay-as-you-go system. Only the share paid by employees is introduced in households' budget constraint. Taxes depend in a non-linear fashion on the level of wages through contributions collected by mandatory complementary schemes, while proportional taxes are used to finance the general regime. Given the specification of the utility function, the discount rate becomes $\tilde{\beta}=\beta /(1+$ $g)^{(1-\eta)(1-\tilde{\sigma})}$. Taxes finance the retirement system (general regime and complementary schemes):

$$
\Theta(w)=\underbrace{\theta w}_{\text {General Re gime }}+\underbrace{\theta_{1} \min \left(w, \text { Ceiling }^{S S}\right)+\theta_{2} \max \left(0, w-\text { Ceiling }^{S S}\right)}_{\text {Complementary schemes }}
$$

where

$$
\begin{aligned}
& \text { Under Ceiling } S S \\
\theta_{1}= & \theta^{M C S N E} c_{1}^{M C S N E} \\
& \text { Above Ceiling SS } \\
\theta_{2}= & \left\{\begin{array}{cl}
\theta^{M C S N E} c_{2}^{M C S N E} & \text { if non executive (blue collars and middle employees) } \\
\theta^{M C S E} c_{2}^{M C S E} & \text { if executive }
\end{array}\right.
\end{aligned}
$$

2. Choice when adult $(s \in A)$

When adult, the individual faces employment risks at age 59. At this age, individuals face 3 possible states : employed $(e)$, unemployed $(u)$ and pre-retirement $(p)$. Transition to these states obey exogenous probabilities denoted by $\pi_{e}, \pi_{u}, \pi_{p}$. Employment probabilities are 
specific to each social category and given by matrix $\Pi$. Optimal choices are thus solution to:

$$
\begin{aligned}
& v(a, A)=\max _{c \geq 0} u(c, l)
\end{aligned}
$$

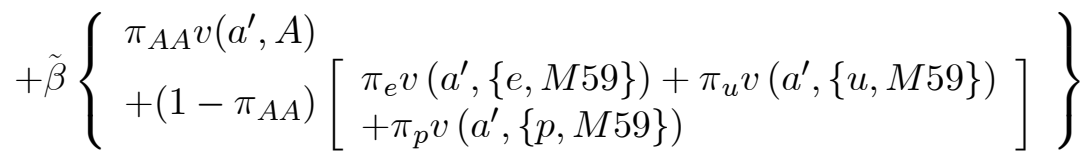

$$
\begin{aligned}
& (1+g) a^{\prime}=(1+r) a+w(A)-\Theta(w(A))-c \\
& a^{\prime} \geq 0
\end{aligned}
$$

As an adult, the individual determines his consumption as a function of her expectations of future income.

3. Choice when mature $(s \in M)$

From the age of 59 on, individuals have the legal right to retire the following year. Each individual compares the future value of being a retiree and the future value of remaining in her current state (employed, pre-retired or unemployed). Mortality risks also intervene in this choice, the probability of death being $\left(1-\pi_{z z^{\prime}}\right)$.

Optimal choices are solutions to the following program

(a) age $z=\{59, \ldots, 69\}$

- If the individual is employed at age $z$

$$
\begin{aligned}
v(a,\{e, z\}) & =\max _{c \geq 0} u(c, l)+\tilde{\beta}\left\{\begin{array}{l}
\left(1-\pi_{z z^{\prime}}\right) \Phi \eta v\left(a^{\prime}, J\right) \\
+\pi_{z z^{\prime}} \max \left[v\left(a^{\prime},\left\{e, z^{\prime}\right\}\right), v\left(a^{\prime},\left\{R, z^{\prime}\right\}\right)\right]
\end{array}\right\} \\
(1+g) a^{\prime} & =(1+r) a+w(z)-\Theta(w(z))-c \\
a^{\prime} & \geq 0
\end{aligned}
$$

When an individual dies, he gives birth to a Young whose social group is determined by the mobility matrix $\Phi$.

- If the individual is unemployed at age $z$

$$
\begin{aligned}
v(a,\{u, z\}) & =\max _{c \geq 0} u(c, l)+\tilde{\beta}\left\{\begin{array}{l}
\left(1-\pi_{z z^{\prime}}\right) \Phi \eta v\left(a^{\prime}, J\right) \\
+\pi_{z z^{\prime}} \max \left[v\left(a^{\prime},\left\{u, z^{\prime}\right\}\right), v\left(a^{\prime},\left\{R, z^{\prime}\right\}\right)\right]
\end{array}\right\} \\
(1+g) a^{\prime} & =(1+r) a+\theta^{u} w(z)-c \\
a^{\prime} & \geq 0
\end{aligned}
$$

where $\theta^{u}$ denotes the replacement ratio associated with unemployment benefits. Notice that unemployed people do not contribute to the system. Unemployment insurance pays for unemployed people.

- If the individual is pre-retired at age $z$

$$
\begin{aligned}
v(a,\{p, z\}) & =\max _{c \geq 0} u(c, l)+\tilde{\beta}\left\{\begin{array}{l}
\left(1-\pi_{z z^{\prime}}\right) \Phi \eta v\left(a^{\prime}, J\right) \\
+\pi_{z z^{\prime}} \max \left[v\left(a^{\prime},\left\{p, z^{\prime}\right\}\right), v\left(a^{\prime},\left\{R, z^{\prime}\right\}\right)\right]
\end{array}\right\} \\
(1+g) a^{\prime} & =(1+r) a+\theta^{p} w(z)-c \\
a^{\prime} & \geq 0
\end{aligned}
$$


where $\theta^{p}$ denotes the replacement ratio associated with pre-retirement. As unemployed workers, pre-retired people do not contribute to the pay-as-you-go system. The State as well as unemployment insurances pay for pre-retired people.

- If retiree at age $z$

For these individuals, retirement has been chosen. The only choice they face is their consumption profile and the optimal amount of financial asset they want to give to their children, given the social mobility matrix. Their behavior are solutions to the following program:

$$
\begin{aligned}
v(a,\{R, z\}) & =\max _{c \geq 0} u(c, l)+\tilde{\beta}\left\{\left(1-\pi_{z z^{\prime}}\right) \Phi \eta v\left(a^{\prime}, J\right)+\pi_{z z^{\prime}} v\left(a^{\prime},\{R, z\}\right)\right\} \\
(1+g) a^{\prime} & =(1+r) a+\omega(z)-c \\
a^{\prime} & \geq 0
\end{aligned}
$$

where $\{R, z\}$ denotes that the individual is a retiree of age $z$.

(b) An individual of age 69

Employed, Unemployed and Pre-retired people automatically become retiree. Decisions rules are the following:

- If employed at age 69

$$
\begin{aligned}
v(a,\{e, 69\}) & =\max _{c \geq 0} u(c, l)+\tilde{\beta}\left\{\left(1-\pi_{z z^{\prime}}\right) \Phi \eta v\left(a^{\prime}, J\right)+\pi_{z z^{\prime}} v\left(a^{\prime}, R\right)\right\} \\
(1+g) a^{\prime} & =(1+r) a+w(69)-\Theta(w(69))-c \\
a^{\prime} & \geq 0
\end{aligned}
$$

- If unemployed at age 69

$$
\begin{aligned}
v(a,\{u, 69\}) & =\max _{c \geq 0} u(c, l)+\tilde{\beta}\left\{\left(1-\pi_{z z^{\prime}}\right) \Phi \eta v\left(a^{\prime}, J\right)+\pi_{z z^{\prime}} v\left(a^{\prime}, R\right)\right\} \\
(1+g) a^{\prime} & =(1+r) a+\theta^{u} w(69)-c \\
a^{\prime} & \geq 0
\end{aligned}
$$

- If pre-retired at age 69

$$
\begin{aligned}
v(a,\{p, 69\}) & =\max _{c \geq 0} u(c, l)+\tilde{\beta}\left\{\left(1-\pi_{z z^{\prime}}\right) \Phi \eta v\left(a^{\prime}, J\right)+\pi_{z z^{\prime}} v\left(a^{\prime}, R\right)\right\} \\
(1+g) a^{\prime} & =(1+r) a+\theta^{p} w(69)-c \\
a^{\prime} & \geq 0
\end{aligned}
$$

(c) If retirement occurs at age 70

The individual determines her consumption behavior by solving:

$$
\begin{aligned}
v(a, R) & =\max _{c \geq 0} u(c, l)+\tilde{\beta}\left\{\left(1-\pi_{z z^{\prime}}\right) \Phi \eta v\left(a^{\prime}, J\right)+\pi_{z z^{\prime}} v\left(a^{\prime}, R\right)\right\} \\
(1+g) a^{\prime} & =(1+r) a+\omega(R)-c \\
a^{\prime} & \geq 0
\end{aligned}
$$




\section{B The French retirement system}

The description of the French retirement system draws on Blanchet and Pelé [1997].

\section{B.1 Benefits from the basic General Regime (GR)}

We present the rules of the basic regime applied to the people who retire before year 2008. The normal retirement age is 60 years old. The pension depends on three elements: the reference wage, the pension rate and the numbers of quarters of contribution. The pension is based on the following formula for an individual of age $z$ :

$$
\omega^{\text {basic }}(z)=\frac{d}{150} \times w^{\text {ref }}(z) \times \phi
$$

where $d$ stands for the number of contributing quarters to the General regime. Periods of unemployment or pre-retirement are included in $d$ since the GR receives transfers from the unemployment insurance services. The latter contribute to the PAYG system on behalf of unemployed and pre-retired. These payments are taken into account when computing the balance of the GR system (section 2.4).

The wage $w^{r e f}(z)$ refers to the average annual gross wage of the best 10 years of one's career. Wages are truncated to the Social Security ceiling that prevailed each year such that the reference wage is

$$
w^{r e f}(z)=\frac{1}{N} \sum_{n=1}^{10} \operatorname{Min}\left(w_{n}(z), \text { Ceiling }^{S S}\right)
$$

where $w_{n}(z)$ and Ceiling ${ }^{S S}$ denote the wage of the best $N=10$ years and the Social Security ceiling. The presence of the Social Security ceiling limits the replacement ratio for executives whose wages are higher than Ceiling ${ }^{S S}$.

The pension rate $\phi$ equals at most $50 \%$. An individual is eligible to receive this "full rate" ( $\phi=0.5$ ) once she contributed 150 quarters to the general regime or at the age of 65 whatever the number to quarters of contribution. If retirement occurs before one of these conditions is met, the individual faces a reduced pension rate equalled to $50 \%$ minus $1.25 \%$ per quarter missing to reach either the age of 65 (260 quarters) or 150 contributing quarters. $\phi$ is written as

$$
\phi=0.5-0.0125 \times \max \{0, \min [260-z \times 4,150-d)]\}
$$

Our proxy for $d$ is based on the difference between the current age $z$ and the age of the end of education.

Formula (8) provides a large incentive to wait until the individual reaches the full rate before claiming the Social Security benefits. Indeed, retiring before 150 quarters of contribution implies not only a reduced pension rate $\phi$ but also a lower share of the reference wage included in the pension (through the "proratization" term $\frac{d}{150}$ in equation (8)).

In 1993, the Balladur reform increased the required number of years of contributing years from 150 quarters to 160 quarters without affecting the "proratization" term. Equation (8) then becomes

$$
\begin{aligned}
\omega^{\text {basic }}(z) & =\min \left(1, \frac{d}{150}\right) \times w^{\text {ref }}(z) \times \phi \\
\phi & =0.5-0.0125 \times \max \{0, \min [260-z \times 4, \mathbf{1 6 0}-d)]\}
\end{aligned}
$$


Moreover, the reference wage is an average of the best $N=25$ years, which tends to lower $w^{r e f}(z)$ for the people who went through unemployment episodes during their career. This reform is implemented so gradually that its full impact on retirement age will be observed only in year 2008. Subsection 3.2 checks that the model replicates the distribution of retirement age observed in the 1990s. We then attempt to predict the consequences of the Balladur reform on retirement decisions.

With incentive schemes, equation (10) becomes

$$
\begin{aligned}
\omega^{\text {basic }}(z)= & \frac{d}{150} \times w^{r e f}(z) \times \phi \\
\phi= & 0.5-0.0125 \times \max \{0, \min [280-z \times 4,160-d)]\} \\
& +\lambda_{2}^{*}(z) \max (0, d-160)
\end{aligned}
$$

\section{B.2 Benefits from complementary schemes : MCSNE and MCSE}

Complementary schemes rely on defined contribution plans. "Points" are purchased by each individual during her career. Each year, a fixed proportion $c$ of wage $w$ is devoted to the purchase of these points. One euro of earning yields $1 / p^{M C S N E}$ points. The contribution rate $\tau$ is fixed by MCSNE and MCSE each year. At the age of retirement, points are converted into euros of pension by multiplying the number of points by a coefficient denoted $v_{d}$ (value of the point). The pension at age $z$ then amounts to

$$
\omega^{M C S N E}(z)=\operatorname{points}(z) \times v_{d} \times \operatorname{penalty}(z)
$$

where points $(z)=\sum_{i=1}^{z} \frac{c(i) w(i)}{p^{M C S N E}(i)}$ denotes the total number of points accumulated throughout the years, $v_{d}$ the value of each point at the date of retirement. If one chooses to retire before contributing 150 quarters (160 quarters under the Balladur reform) to the system or before the age of 65 , penalties (penalty $(z)$ ) are applied to the pension that then decreases by approximately $4 \%$ each year missing to reach age 65 . For non executives, contributions are collected by MCSNE. Different contribution rates are applied to the part of the wage below and above the Social Security ceiling. For executives, MCSNE (respectively MCSE) collects the contribution for the part of the wage below (respectively above) the Social Security ceiling.

Finally, MCSNE and MCSE introduce a wedge between the contribution rate paid by workers $\left(c^{\prime}\right)$ and the contribution rate that grants them points $(c)$. In the data, $c^{\prime}>c$ : by imposing this discrepancy between the tax paid and tax giving the right to points, complementary schemes anticipate the expected deficit associated with the future demographic change. MCSNE and MCSE apply different wedges. Let $\frac{c_{M C S N E}^{\prime}}{c_{M C S N E}}=\theta^{M C S N E}$ (respectively $\frac{c_{M C S E}^{\prime}}{c_{M C S E}}=\theta^{M C S E}$ ) be the wedge used by MCSNE (respectively MCSE) for the part of the wage below and above the Social Security ceiling. $\theta^{M C S E}$ and $\theta^{M C S N E}$ are endogenously determined at the stationary equilibrium.

\section{B.3 Calibration of the French pension system}

The Social Security ceiling used to compute the pensions paid by the general regime and complementary schemes is set to its 1994 value, i.e. 156720 Frs a year. 
The calibration of parameters of complementary schemes in equations (11), (6) and (1) are given by tables 15 and 16. These values correspond to the ones prevailing in 1994 and were provided by MCSNE and MCSE. Today $2 / 3$ of the contributions to the complementary schemes are paid by employers. We assume that this ratio is not modified.

Table 15: MCSNE : ARRCO complementary scheme

\begin{tabular}{cccc}
\hline \hline$c_{1}^{A R R C O}$ & $c_{2}^{A R R C O}$ & $p^{A R R C O}$ & $v_{d}^{A R R C O}$ \\
\hline 0.04 & 0.1 & 22.4 & 2.455 \\
& & & \\
\hline \hline
\end{tabular}

Table 16: MCSE : AGIRC complementary scheme

\begin{tabular}{ccc}
\hline \hline$c_{2}^{A G I R C}$ & $p^{A G I R C}$ & $v_{d}^{A G I R C}$ \\
\hline 0.12 & 19.52 & 2.303 \\
& & \\
\hline \hline
\end{tabular}

Table 17 presents the value of penalties (equation (11)).

Table 17: Penalties

\begin{tabular}{l|cccccccccc}
\hline \hline age & 55 & 56 & 57 & 58 & 59 & 60 & 61 & 62 & 63 & 64 \\
penalty & 0.43 & 0.50 & 0.57 & 0.64 & 0.71 & 0.78 & 0.83 & 0.88 & 0.92 & 0.96 \\
\hline \hline
\end{tabular}

At the stationary equilibrium, the wedges $\theta^{M C S N E}$ and $\theta^{M C S E}$ endogenously adjust to balance the budget of complementary schemes.

\section{References}

Arrondel, L. and F. Laferrère, Sucessions et Héritiers À Travers Les Données Fiscales, Economie et Prévisions, 1996, 100-101.

Artus, P., Déficit Public, Théorie et Pratique, Economica, 1996.

Attanasio, O. P., J. Banks, C. Meghir, and G. Weber, Humps and Bumps in Lifetime Consumption, Journal of Business and Economic Statistics, 1999, 1\%.

Bac, C., C. Bonnet, O. Bontout, and G. Cornilleau, Exercices de Simulation de L'évolution À Long Terme Du Système Des Retraites, Document de travail DREES 38, DREES Octobre 2000 . 
Berkovic, J. and S. Stern, Job Exit of Older Men, Econometrica, 1991, 59 (1), 189-210.

Blanchet, D. and G. Pelé, Social Security and Retirement in France, NBER Working Paper 6214, NBER October 1997.

and J. A. Monfort, L'âge et la Durée de la Retraite Depuis 50 Ans, INSEE Première, Avril 1996, 448.

Castañeda, A. J., J. Diaz-Gimenez, and V. Rios-Rull, Earnings, Wealth Inequality and Income Taxation: Quantifying the Trade-Offs of Switching the U.S. To a Proportional Income Tax System, Mimeo, Penn University 1998.

Charpin, J. M., Rapport Au Premier Ministre : L'avenir de Nos Retraites, Documentation Française, 1999.

Coile, C., P. Diamond, J. Gruber, and A. Jousten, Delays in Claiming Social Security Benefits, Journal of Public Economics, 2002, 84, 357-385.

Colin, C., V. Iéhlé, and R. Mahieu, Les Trajectoires de Fin de Carrière Des Salariés Du Secteur Privé, Solidarité-Santé, 2000, (3).

COR, Retraites : Renouveler Le Contrat Social Entre Les Générations, Conseil d'Orientation des Retraites, 2001.

Diamond, P.A. and J. A. Hausman, Individual Retirement and Savings Behavior, Journal of Public Economics, 1984, 23, 81-114.

Fuster, L., Is Altruism Important for Understanding the Long-Run Effects of Social Security?, Review of Economics Dynamics, 1999, 2, 616-637.

_ A. Imrohoroglu, and S. Imrohoroglu, A Welfare Analysis of Social Security in a Dynastic Framework, International Economic Review, November 2003, 44 (4), 1247-1273.

Gruber, J. and D. Wise, Social Security and Retirement: An International Comparison, American Economic Review, May 1998, 88 (2), 158-163.

Gustman, A. L. and T. L. Steinmeier, The Social Security Early Entitlement Age in a Structural Model of Retirement and Wealth, NBER Working Paper 9183, NBER September 2002.

Imrohoroglu, A., S. Imrohoroglu, and D. H. Joines, Computational Models of Social Security: A Survey, in R. Marimon and A. Scott, éditeurs, Computational Methods for the Study of Dynamic Economies, Oxford University Press 1999, pp. 221-237.

INSEE, Mobilité Sociale Tome Deux, Vol. 89-90-91 of Emploi et Revenus, 1995.

__ L La Situation Démographique En 1996, Vol. 49-50 of Résultats, 1996.

__ , La Structure Des Salaires En 1994, Vol. 146-147 of Emploi et Revenu, 1999.

Revenu et Patrimoine Des Ménages, Vol. 28 of Synthèses, 1999.

Kahn, J. A., Social Security, Liquidity and Early Retirement, Journal of Public Economics, 1988, 35, 97-117. 
Rust, J., A Dynamic Programming Model of Retirement Behavior, in D. Wise, éditeur, The Economics of Aging, Chicago Press, 1989, pp. 359-398.

_ a and C. Phelan, How Social Security and Medicare Affect Retirement Behavior in a World of Incomplete Markets, Econometrica, 1997, 65 (4), 781-831.

Sargent, T. J. and L. Ljungqvist, Recursive Macroeconomic Theory, Cambridge, Massachusetts: MIT Press, 2000.

Stock, J. and D. Wise, Pensions, the Option Value of Work, and Retirement, Econometrica, 1990, 58 (5), 1151-1180.

VanDerKlaauw, H. and K. I. Wolpin, Social Security, Pensions and the Savings and Retirement Behavior of Households, Mimeo November 2002. 